\title{
Beiträge
}

\section{zur vergleichenden Anatomie der} Rubiaceen.

\section{Inaugural-Dissertation zur}

\author{
Erlangung der Doktorwürde
}

der

Hohen philosophischen Fakultät der Georg-August-Universität zu Göttingen

vorgelegt von

\section{H. Tolle}

aus Großbodungen (Kreis Worbis).

Götting en 1913.

Druck der Dieterichschen Universitäts-Buchdruckerei

(W. Fr. Kaestner). 
Angenommen von der math.-naturwissenschaftlichen Abteilung.

Tag der mündlichen Prüfung: 16. Juli 1913.

Referent: Herr Geh. Reg.-Rat Prof. Dr. Peter. 
In der Einleitung zu seiner Arbeit »Über den systematischen Wert der Holzstruktur bei den Dikotyledonen " sagt Solereder im Hinblick auf das reiche Untersuchungsmaterial und auf die anatomischen Charaktere, die Radlkofer bei seiner anatomischen Methode für das Pflanzensystem benutzte, daß »die völlige Ausbildung der Methode noch sehr viele Arbeitskräfte beanspruchen wird «. Er selbst gibt im obengenannten grundlegenden, 140 Familien umfassenden Werk eine Darstellung der Anatomie des Holzes in fast sämtlichen Familien der Dikotyledonen, und beantwortet auf Grund seiner Ergebnisse die Frage: »Finden sich im allgemeinen in der Struktur des Holzes charakteristische Merkmale, welche für einen größeren oder geringeren Verwandtschaftskreis konstant sind? « dahingehend, daß »die Anatomie des Holzes für bestimmte Familien, Triben, Gattungen und Arten wertvolle Charaktere liefert «. Im speziellen Teil seiner Arbeit gibt er in den Resultaten eine vorläufige Übersicht der vorkommenden Übereinstimmungen und Verschiedenheiten im anatomischen Bau des Holzes der behandelten Familien, erklärt aber selbst, daß es zur Erhärtung und Erweiterung seines durch "orientierende Untersuchung "Gewonnenen noch weiterer spezieller Arbeiten bedarf. - Wenn sich auch die Erwartung Theodor Hartig's, die Holzanatomie würde das »aus Äußerlichkeiten « abgeleitete System völlig verdrängen, nicht im entferntesten erfüllt hat, so beweisen doch die Arbeiten von Möller, Sanio, Molisch, Michael, Engler u. a., daß im natürlichen System neben den morphologisch äußeren, auch die 
morphologisch inneren, d.h. die anatomischen Merkmale berücksichtigt werden müssen. Am besten beweist Radlkofers Monographie über "Serjania " die Wichtigkeit der Anatomie für die Systematik und die Untersuchung der Ebenaceen von Molisch die Beziehung zwischen Histologie und Systematik, denn Molisch findet unter den Ebenaceen eine so auffallende anatomische Übereinstimmung, »daß es selbst dem Geübten, wenn er unwesentliche Merkmale, als Färbung und Größenverhältnis der Elemente außer acht läßt, unmöglich wird, die Genera, geschweige denn die Spezies zu unterscheiden «.

$\mathrm{Da}$ spezielle Arbeiten über den anatomischen Bau der Rubiaceenachsen außer Möllers und Michaels nicht sehr zahlreichen Untersuchungen vorliegen, und Möllers Aufstellung des »einzigen durchgreifenden Charakters « - keinerlei Beziehung des Holzparenchyms zu den Gefäßen und radiale Anordnung des Holzparenchyms - durch Michaels Arbeit hinfällig wurde, Michael selbst die Rubiaceen nach dem Bau der Markstrahlen und dem Vorkommen von hof- und einfachgetüpfeltem Libriform in drei Gruppen einteilte, die sich auf die Verwandtschaft zu den Caprifoliaceen und den Compositen beziehen, habe ich auf die Anregung meines hochverehrten Lehrers, Herrn Geh. Regierungsrat Prof. Dr. A. Peter, es unternommen, größtenteils erst in neuerer Zeit aufgestellte Arten aus beiden Triben der sehr großen Familie der Rubiaceen anatomisch zu untersuchen, um auf Grund der Ergebnisse unter Hinzuziehung von Solereders allgemeinen und Michaels speziellen Angaben festzustellen, ob sich innerhalb dieser Familie wirklich keine weiteren Verwandtschaftsverhältnisse im histologischen Bau zu erkennen geben, bezw., um das schon gefundene zu bestätigen.

Das Untersuchungsmaterial stammt ausschließlich aus unseren afrikanischen Kolonien, ist von verschiedenen Botanikern gesammelt worden und darf als sicher bestimmt angesehen werden. Der Direktor des Kgl. Botanischen Museums zu Dahlem-Berlin, Herr Geh. Oberregierungsrat Prof. Dr. Engler, 
überließ es in dankenswerter Weise dem Göttinger Botanischen Institut zur Bearbeitung. Zur Verfügung standen meist mehr oder weniger lange, fast immer mit Rinde umkleidete, ganze oder geteilte Achsenstücke.

Was die in vorliegender Abhandlung benutzte Nomenklatur betrifft, so schließt sie sich der Solereder's, also der älteren Bezeichnungsweise an. Nach dieser setzt sich das Holz aus Gefäßen, Libriform (Prosenchym), Holzparenchym und Markstrahlparenchym zusammen. $\mathrm{Da}$ sich das Markstrahlparenchym fast bei allen untersuchten Arten differenziert in radial- und in achsial gestreckte Markstrahlzellen, so habe ich die einen als »liegende", die anderen als »stehende" bezeichnet (Kny's Merenchym- und Markstrahlpalissaden). Charakterisiert werden die »liegenden « außer der radialen Streckung noch durch radial verlaufende Interzellularen zwischen den Zellreihen. Zwischenstufen zwischen beiden Zellenarten ergeben auf dem Tangentialschnitt schwach achsialgestreckte, auf dem Radialschnitt isodiametrischen Anblick. Als hofgetüpfeltes Libriform bezeichne ich dasjenige, welches auf dem Querschnitt einen, wenn auch oft kleinen Hof zeigt. Die Gefäßlumina nenne ich bei der makroskopischen Betrachtung Gefäßporen.

Neben der Hauptabsicht, einen Beitrag zur Holzanatomie der Rubiaceen auf Grund neuer Materialien zu liefern, wurde noch der Nebenzweck verfolgt, eine neue Methode zur Herstellung von Holzschliffen zu erproben, bezw. die Methode, deren sich die Geologie in jüngster Zeit zur Herstellung von Steinschliffen bedient, für den Gebrauch in der Botanik auszubauen. Die bisherigen Methoden zur Herstellung von Pflanzen- und Samenschliffen waren zu umständlich und für Holzschliffe nicht praktisch. Da die vorliegende Arbeit die erste ist, die sich dieser Methode zur Herstellung von Präparaten im Großen bedient, möge eine Beschreibung des Apparates und der Herstellung der Schliffe, wie ich sie nach vielen Versuchen am vorteilhaftesten halte, folgen. - Es sind 
zwei zylindrische, an einem Ende geschlossene Glasröhren ineinander gestülpt. In der äußeren befindet sich bei $160^{\circ}$ siedendes Pseudocamol über einem Bunsenbrenner. Sie ist oben durch eine mit einem runden Loch von dem Umfange der zweiten engeren Röhre versehene Bleiplatte verschlossen. Durch diese Öffnung taucht die kleinere in die weitere so, daß zwischen ihrem Boden und der Pseudocamolfläche 1 bis $2 \mathrm{~cm}$ Raum bleibt. In dieser inneren Röhre befindet sich 4-5 cm hoch ein Harzpräparat, Collolith genannt, das auch im Vakuum bis $170^{\circ}$ keine flüchtigen Substanzen abgibt. Dieses Collolith wird nun durch die die innere Röhre umspülenden, heißen Pseudocamoldämpfe, die sich in 10-15 cm Höhe wieder kondensieren, geschmolzen und dann mit dem zu schleifenden Holzklötzchen beschickt. Voraussetzung für die Beschickung ist größte Trockenheit des Holzes, die man ja leicht bei frischen Stücken im Trockenofen erreichen kann. Diese Klötzchen habe ich meist so geschnitten, bezw. gesägt, daß sie 3-4 mm Dicke und $1-3 \mathrm{qcm}$ Fläche besaßen. Von diesen Stücken können zu gleicher Zeit alle drei Schnitte, Radial-, Tangential- und Querschnitt, eingetaucht werden. Sehr zweckmäßig ist es, jedes Klötzchen an einem Draht von Röhrenlänge zum bequemen Herausholen zu befestigen. Die Collolithröhre ist durch einen starken Gummipfropfen verschlossen, durch dessen mittlere Öffnung hindurch eine luftdichte Verbindung mit einer Wasserstrahlluftpumpe hergestellt wird. Durch diese wird nun die Collolithröhre evakuiert und auf diese Weise die in dem Holzklötzchen enthaltene Zellenluft herausgesogen. Die Luft braust beim Beginn der Evakuation naturgemäß stark in die Höhe. Die Verbindungsrôhre trägt kurz über dem Gummipfropfen einen doppelt durchbohrten Hahn, der einerseits die Verbindung zwischen Pumpe und Rezipient, andererseits bei Drehung um $90^{\circ}$ eine Verbindung des Rezipienten mit der atmosphärischen Luft herstellt. Abwechselnd wird nun evakuiert und Luft eingelassen, bis die herausgesogene Luft nicht mehr hoch 
aufbraust. Dann kann dauernd evakuiert werden. Außerdem ist zwischen Pumpe und Rezipient noch ein Vakuummeter eingeschaltet, das das Funktionieren der Wasserstrahlpumpe anzeigt. Nach der jeweiligen Verbindung des Rezipienten mit der atmosphärischen Luft muß selbstverständlich das Vakuummeter geschlossen werden, da sonst das hochschnellende Quecksilber die geschlossene Manometerröhre zersplittern würde. Da das Collolith selbst keine flüchtigen Produkte liefert, so ist man sicher, daß die in der Vakuumröhre entstehende Luft nur aus dem Holzklötzchen stammen kann. Man muß nun solange evakuieren, bis die durch das Harz hindurch deutlich sichtbare Luftblasenentwicklung auf ein Minimum reduziert ist (ungefähr nach 2 Stunden). Die an dem Draht befestigten Holzklötzchen werden dann herausgezogen und abgekühlt. Das Collolith ist in eine Tiefe von $1-2 \mathrm{~mm}$ in das Holz eingedrungen und bietet nach dem Erstarren beim Schleifen den Zellen einen festen, stützenden Halt. Nach Erkalten der Klötzchen werden diese auf der mit feuchtem, feinem Schmirgel bedeckten Glasplatte auf der einen Fläche glatt geschliffen. Nach meinen Versuchen halte ich es dann für unumgänglich notwendig, die so geschliffene Fläche noch auf einem mit Glycerin oder Wasser befeuchteten Arkansasschiefer zu polieren, da durch den groben Schmirgel doch die Zellwände etwas zerrissen werden. Es genügt ein Polieren von 2-3 Minuten. Bei diesem ersten Schleifen nehme man aber nicht zu viel Holz weg, da das Collolith nur die äußerste Schicht völlig durchtränkt. Dann folgt Abwaschen (glatte Fläche mit einem Pinsel, um noch anhaftenden Schmirgel $\mathrm{zu}$ entfernen) und Trocknen an Luft. Mit Hülfe des Kittapparates werden die Klötzchen nun auf starke, an den Rändern rundgeschliffene Objektträger durch einen großen Collolithtropfen aufgekittet und dann auf Schmirgel mikroskopisch dünn geschliffen. Nachdem auch die äußere Fläche auf dem Arkansasschiefer genügend poliert ist, folgt Trocknen und Abschwimmenlassen in Xylol, das das ein- 


\section{$-8-$}

gedrungene Collolith wieder löst. Vom Xylol tat ich die Schliffe in Alkohol, um anhaftendes Wasser zu entfernen; von hier wieder in Xylol, wo die Schliffe nochmals mit dem Pinsel gereinigt wurden, worauf dann die Einbettung in Canadabalsam erfolgte. Ich machte die Erfahrung, daß hauptsächlich Querschliffe trotz peinlicher Säuberung etwas Schmirgel behielten und sich auch etwas wellten, was bei der mikroskopischen Untersuchung sehr störend wirkt. Diesen beiden Übelständen kann aber dadurch abgeholfen werden, daß man einerseits sehr hartes Collolith verwendet (es wird in verschiedenen Härten geliefert), andererseits die Schliffe nach der Einbettung in einfache Klammern sanft preßt und in dem Trockenofen das Präparat trocknen läßt.

So umständlich und langwierig diese Methode zu sein scheint, so bekommt der Anatom, wenn er obige erprobte Angaben genau beobachtet, schon nach einigen Tagen genügende Übung, soda $B$ er täglich bequem 6 Klötzchen evakuieren und während dieser nur im Anfang sich nicht selbst betätigenden Arbeit 6 andere aufkitten, schleifen und einbetten kann. Die fertigen Präparate bieten den Schnittpräparaten gegenüber bei der Beantwortung vieler anatomischer Fragen große Vorteile. Ein Querschliff durch einen $2 \mathrm{~cm}$ dicken Zweig oder Stamm zeigt in einem Stück Mark, Holzkörper und Rinde. So ist die Jahrringbildung der tropischen Hölzer in ihrem vollen Umfange und allen Einzelheiten viel leichter und sicherer zu erkennen; äußerst harte Hölzer, wie die Ebenaceen und viele andere tropische Arten, setzen dem Schneiden große Schwierigkeiten entgegen oder erleiden durch aufweichende Behandlung Veränderungen, wie Quellen der Wände und Lösung von Inhaltsstoffen; sehr schöne Präparate erhält man beim Schleifen größerer Krankheitsherde, wie bei dem von Polyporus und Stereum durchwucherten Holzgewebe, wo dieses pulverisierbar ist und so ein Schneiden unmöglich macht. Bei Anomalien und inneren Ästen bekommt man ganz vorzügliche Bilder mit ihrer gesamten Um- 
gebung und kann nun die Lagerung und Veränderung der einzelnen Elemente genau in ihrer Gesamtheit beobachten. Bei Sabicea calycina fand ich z. B. das ganze Holz von Pilzfäden und Pilzknäueln längs und quer durchzogen, und konnte so die Färbung des Holzes durch diese Pilze nachweisen. Zur Kontrolle habe ich von sämtlichen untersuchten Rubiaceen auch Schnittpräparate angefertigt, denen ich keineswegs den Vorzug geben möchte. Nur bei der Anfertigung der Radialschliffe muß ich peinlichste Sorgfalt empfehlen, daß den meist sichtbaren Markstrahlen genau parallel gesägt wird. Man bekommt sonst nie längere Stücke eines Markstrahls unter das Mikroskop.

Als Ergebnis meiner Versuche mit dieser Schleifmethode kann ich mitteilen, daß ich sie in allen oben genannten Fällen, wo Härte, Größe des Objektes oder die Gefahr der Pulverisierung u. a. m. dem Schneiden Schwierigkeiten oder dieses gar zur Unmöglichkeit macht, für äußerst vorteilhaft und praktisch halte.

Die beigegebenen Figuren sind nach Photographien von Schliffen angefertigt.

Die Arbeit wurde im botanischen Institut in Göttingen ausgeführt. Meinem hochverehrten Lehrer, Herrn Geh. Regierungsrat Prof. Dr. A. Peter, der die Versuche und Untersuchungen veranlaßte, spreche ich für die gütige Förderung, die er mir im Verlauf derselben zuteil werden ließ, meinen innigsten Dank aus. 
Corynanthe macroceras K. Sch. leg. Standt 20.

Kamerun.

Cinchonoideae. Cinchoninae. Cinchoneae.

Das vorliegende Achsenstück stammt aus Lolodorf, Kamerun, hat $5 \mathrm{~cm}$ Durchmesser, kleines dunkles Mark und unsere Rotbuchenholzfarbe. Zuwachszonen sind als breitere helle und dunkle schmale, wellige Ringbildungen deutlich $\mathrm{zu}$ sehen. Poren und Markstrahlen sind mit freiem Auge unkenntlich, unter der Lupe sehr gut sichtbar. Die Rinde ist dunkelbraun und $1^{1 / 2} \mathrm{~mm}$ dick. Das Holz ist sehr hart und liefert nach Wehner »Pflanzenstoffe» falsche Johimberinde mit sehr wenig Johimbin, aber reichlich physiologisch unwirksame Nebenalkaloide.

Die makroskopisch deutliche Jahrringbildung wird hervorgerufen durch starke Anhäufung der Holzparenchymketten, durch etwas weitlichtigeres, dünnwandigeres Libriform und zahlreichere Gefäße im Frühholz (helle Ringzeichnung), durch Einzelstellung des Parenchyms, kleinere Gefäße und stärker zusammengepreßtes Libriform im Spätholz. Eine scharfe Grenze zwischen Früh- und Spätholz besteht nicht.

Zwischen den zahlreich vorhandenen Markstrahlreihen steht das Libriform in radialer Anordnung. Es hat durch nicht $\mathrm{zu}$ starke Zusammenpressung rundlichen, höchstens schwach abgeplatteten, unregelmäßig polyedrischen Zellenquerschnitt, läßt bei gegenseitiger Angrenzung Interzellularen frei und erscheint auf denı Querschnitt hofgetüpfelt. Die Libriformfasern besitzen eine Wandstärke von 5,2 $\mu$ und 
$7,8 \mu$ Lumendurchmesser. Sie endigen in ziemlich kurzer, bajonettartiger Spitze und sind spärlich mit reihenförmig übereinandergestellten, spaltenförmigen Hoftüpfeln versehen. Der Hof ist länglich und mißt $5,4 \mu$ im Durchmesser; der Spalt ist kleiner als der Hof. Die Fasern schmiegen sich den Markstrahlen eng an und erfahren dadurch abwechselnde Verengerung und Erweiterung ihres Lumens und gewundene Form. Bei nebeneinanderliegenden Fasern kreuzen sich die Tüpfel.

Das Holzparenchym zeigt sich teils einzelstehend, teils in kurzen, einreihigen tangentialen Ketten. Meist verbinden diese Ketten nur zwei benachbarte Markstrahlen; seltén durchziehen sie zusammenhängend zwei Holzstränge. Das Holzparenchym ist dünnwandig, höchst unregelmäßig konturiert und mit gelb- bis rotbraunem Inhalt vollgepfropft. Es ist bei Berührung mit Libriform und Markstrahlparenchym spärlich, bei Angrenzung an Gefäße reichlich porös getüpfelt, wie gewöhnlich geformt und verdickt.

Die auf dem ganzen Querschnitt zerstreut, nur im Frühholz oft in radialen Reihen zu 2-4 liegenden Gefäße haben wenig unterschiedliche, kreisrunde oder elliptische Lumina von durchschnittlich $60 \mu$ Durchmesser. Die Gefäßglieder sind kurz und von schwach geneigten, oft horizontalen Scheidewänden begrenzt, die fast ganz resorbiert sind. Die Perforation ist elliptisch. Zahlreiche kleine Tüpfel mit $3 \mu$ großem Hof und horizontalgestellter, spaltförmiger Öffnung durchbrechen ihre Seitenwände. Berührt die Gefäßwand Markstrahlparenchym, so sind die Hoftüpfel etwas größer und länglich.

Den Querschnitt durchziehen die ein- bis zweireihigen Markstrahlen in sehr großer Anzahl. Ihre Zellen führen zum größten Teil dunkelbraunen Inhalt und sind wenig radial gestreckt. Auffallend ist ihre bauchige Vergrößerung in den parenchymreichen Zonen, wo sie merklich radial gestaucht und ausnahmslos mit Inhalt vollgepfropft erscheinen. Auf 
dem Tangentialschnitt sind die Markstrahlen 1-4 Zellen breit und sehr hoch. Die Mitte des Markstrahls ist stets am breitesten und wird immer zum überwiegenden Teil von radial gestreckten Zellen eingenommen. Die Kantenzellen sind stets achsial langgestreckt und bilden eine mehr oder weniger lange Reihe. Durch diese Reihen stehen oft 2 oder 3 Markstrahlen miteinander in Verbindung. Zwischen den »liegenden « Zellen finden sich dreieckige Interzellularen, nach denen hin Tüpfelkanäle führen. Auf dem Radialschnitt sieht man die Wände beiderlei Zellen einfach und äußerst reichlich perforiert. Die Tüpfel der »liegenden « Zellen sind zarter. Diese Zellen sind oft um das vier- bis fünffache ihrer Höhe radial gestreckt und führen nie Inhalt.

Adina microcephala. Hiern. leg. Kersting. 57. Togo.

Cinchonoideae. Cinchoninae. Naucleae.

Das vorliegende Stück ist aus dem Innern eines starken Stammmes herausgeschnitten. Das Holz hat dunkelbraune Farbe, läßt sich leicht schneiden und sägen und liefert ein sich feucht anfühlendes Sägemehl. Zuwachszonen sind stark verwischt, die Gefäßporen als helle Punkte und die Markstrahlen als äußerst feine, helle Streifung makroskopisch kenntlich. Die Markstrahlen verlaufen zum Teil in S-förmigem Bogen und liegen sehr dicht aneinander. Innerhalb der konzentrischen Zuwachszonen kommen noch dunkle, oft nur einige $\mathrm{cm}$ lange Binden vor. Nach mehrtägigem Liegen des Holzes in Wasser ist dieses gelbbraun gefärbt und mit einem festen, nichtglänzenden, schleimigen Überzug bedeckt. Der Boden des Gefäßes und das Holz selbst ist ebenfalls mit dieser schleimartigen Masse versehen.

Jahrringbildung ist mikroskopisch kaum festzustellen. Alle Elemente sind ziemlich gleichförmig über den Querschnitt verteilt.

Den Hauptanteil an der Holzbildung nimmt das Libri- 
form. Es liegt nicht in streng radialer Anordnung, hat rundlichen, seltener polyedrischen Querschnitt und typische Hoftüpfelung. Es, besitzt bei $5,7 \mu$ Wandstärke ein Lumen von. $10,4 \mu$ Durchmesser. Der Hof der Tüpfel ist kreisrund und $5 \mu$ breit; der Spalt ist sehr eng und kleiner als der Hof. Die Tüpfel slnd spärlich und stehen in vertikaler Reihe. Die Mündungen kreuzén sich bei aneinanderlagernden Fasern. Längere gefäßarme, tangentiale Libriformbinden bilden die makroskopisch wahrnehmbaren dunkleren Partien. Die Fasern führen helle, ölige Tröpfchen, die sich mit Sudan gelb und mit Eisenchlorid in alkoholischer Lösung schwarz färben. Außerdem findet man in einigen Fasern eine feinkörnige, gelbe Inhaltsmasse, in der wieder die obengenannten öligen Tröpfchen lagern.

Das Holzparenchym ist äußerst selten. Es steht einzeln, zerstreut im Libriform. Seine Perforation ist spärlich, einfach und rund. Es führt als Wandbelag gelben harzigen Inhalt, der sich an den Querwänden häuft.

Die Gefäße stehen über den ganzen Querschnitt gleichmäßig zerstreut, selten zu $2-3$ in radialer Zusammenstellung. Sie haben elliptischen Umriß mit radial gerichteter großer Achse. Ihr Durchmesser schwankt zwischen 120 und $158 \mu$. Sie sind sehr oft mit einem mehr oder weniger dicken Wandbelag von derselben gelben Masse ausgekleidet, die wir bei dem Holzparenchym schon gefunden haben. Die Wände sind sehr dünn und führen zahlreiche, links spiralig aufsteigende Hoftüpfel. Der Hof ist kreisrund, oft etwas länglich und mißt 5-6 $\mu$ im Durchmesser. Der Spalt ist sehr eng, horizontal gestellt und kleiner als der Hof. Abweichende Tüpfelung bei Berührung mit Markstrahlparenchym ist nicht zu finden. Die Gefäßglieder sind kurz, die Scheidewände schwach geneigt und einfach, rund perforiert.

Die Markstrahlen erscheinen auf dem Querschnitt in 1 - 3reihigen Linien, die entweder aus wenig-, oder aus stark radial gestreckten Zellen bestehen. Auf dem Tangential- 
schnitt ergeben die mehrreihigen Markstrahlen spitz-spindelförmigen Anblick. Ihr mittlerer Teil setzt sich vornehmlich aus »liegenden « Zellen und aus unmerklich achsial gestreckten Zellen zusammen. Die Kante bildet fast immer eine Reihe mehrerer achsial gestreckter »stehender « Zellen. Die letzte Zelle ist stets spitz. Diese Reihen stellen oft zwischen zwei Markstrahlen eine Verbindung her. Die einreihigen Markstrahlen sind ausschließlich aus vertikal sehr langen Zellen zusammengesetzt und werden bis 17 Zellen hoch. Auf dem Radialschnitt zeigen die Wände eine große Anzahl einfacher Tüpfel, die »liegenden « Zellen eine zwei- bis vierfache Länge ihrer Höhe. Zwischen »liegenden " und »stehenden "Zellen befinden sich als Übergang solche von isodiametrischer Form. Der Inhalt der Markstrahlzellen ist der der übrigen Elemente.

\section{Sarcocephalus sambucinus. K. Sch.}

leg. Zenker. 1282. Naucleae.

\section{Kamerun.}

Sarcocephalus sambucinus liefert ein ziemlich leichtes hellfarbiges Holz. Die Jahrringbildung ist stark verwischt, die Gefäße sind als helle Punkte deutlich sichtbar, die Markstrahlen sehr schwach kenntlich. Das Mark hat rostbraune Farbe, eckige Form und $1 \mathrm{~cm}$ im Durchmesser. Nach mehrwöchentlichem Liegen in Wasser bildet sich auf der Oberfläche ein schillernder, fester Hautüberzug, den man wie eine Fetthaut zusammenschieben kann. Die Rinde ist $3 \mathrm{~mm}$ dick.

Grenzen zwischen den Zuwachsszonen sind mikroskopisch nicht festzustellen. Dunkle, makroskopisch wahrnehmbare Partien rühren von kurzen zusammenhängenden Libriformbändern, hellere von Anhäufung des Holzparenchyms her. Der Durchmesser der Gefäße ist in allen Teilen des Querschnitts schwankend.

Aus Libriform setzt sich die Grundmasse des Holzes zusammen. Es steht in radialen Reihen und hat uṇregelmäßig 
polyedrischen Querschnitt. Seine 5-6 $\mu$ starke farblose Wand zeigt reichliche Hoftüpfelung. Das Lumen ist rund oder eckig und hat durchschnittlich $6-6,5 \mu$ großen Durchmesser. Die Hoftüpfel zeigen auf dem Tangentialschnitt 7,8 $\mu$ großen kreisrunden Hof und schmale spaltenförmige, $5 \mu$ lange Mündung. Die Spalten kreuzen sich in benachbarten Zellen. Inhalt führen die Fasern nicht. Die Tüpfel finden sich auf den Tangentialwänden zahlreicher als auf den Radialwänden.

Die Gefäße haben elliptischen Querschnitt mit radialgerichteter, bis $145 \mu$ langer Achse. Sie liegen einzeln, nicht ganz gleichmäßig über dem Querschnitt zerstreut, sondern in größeren Gruppen von 3-12. Die Querwände sind ziemlich stark geneigt und einfach, elliptisch perforiert. Die nur mäßig verdickten Wände tragen reichlich Tüpfel mit runden $5,4 \mu$ großem Hof und spaltenförmiger, zur Längsachse des Gefäßes schief orientierter Mündung. Bei Berührung mit Markstrahlenparenchym tritt keine Veränderung der Tüpfelung ein. Im primären Holz haben die ersten Gefäße sehr enggestellte, spiralige Verdickungsleisten.

Wenig, meist einzeln oder in sehr kurzen tangentialen, einreihigen Ketten stehendes Holzparenchym fällt auf dem Querschnitt durch seinen gelbbraunen Inhalt auf. Fast jedes Gefäß wird von wenig Parenchym begleitet. Die Parenchymzellen sind von gewöhnlicher Form und sehr spärlich getüpfelt.

Der Markstrahlbau weicht nur in der Beziehung von Adina microcephala $a b$, daß bis 5 Markstrahlen miteinander in vertikaler Richtung verbunden werden. Auf diese Weise werden solche zusammengesetzte Markstrahlen bis 90 Zellen hoch. Die den »liegenden «Zellen am nächsten verlaufenden radialen Zellreihen sind im Vergleich zu Adina weniger hoch und weisen einzelstehende, mit kleinsten, unregelmäßigen Kristallen gefüllte Zellen auf. Die Wände der »liegenden «Zellen sind etwas schwächer als die der »stehenden «.

Als Inhalt führen die Elemente dieselben kleinen Öltröpfchen wie Adina. 
Mussaenda tenuiflora Busse. var. grandiflora K. Sch. Usambara. leg. Holst. 2470.

Cinchonoideae. Gardeniinae. Mussaendeae.

Am hellen, $3^{1} / 2 \mathrm{~cm}$ dicken Achsenstück sind Jahrringe schwach sichtbar, Gefäßporen als helle Punkte kenntlich, Markstrahlen unkenntlich. Die Rinde ist $1-2 \mathrm{~mm}$ dick; das Mark hat $0,5 \mathrm{~cm}$ im Durchmesser, ist rund und hell gefärbt.

Jahrringbildungen sind mikroskopisch nicht festzustellen. Irgend welche radiale Verkürzungen der Elemente oder regelmäßig wiederkehrende Unterschiede in Größe und Anzahl der Gefäße sind nicht wahrnehmbar.

Das Libriform bildet die Grundmasse des Holzkörpers. Es hat höchst unregelmäßigen polyedrischen Querschnitt, ist in seiner radialen Anordnung gestört, weitlumig und sehr dünnwandig. Bei sehr schwankender Lumengröße (bis $26 \mu$ Durchmesser) ist seine Wand nur $3 \mu$ stark. Auf dem Tangentialschnitt erscheint es spärlich hofgetüpfelt. Die spaltförmige Mündung ist 5,2 $\mu$ lang, schmal, schiefgestellt und etwas größer als der kreisrunde Hof. Die Hoftüpfel stehen reihenweise übereinander. In benachbarten Fasern kreuzen sich die Tüpfel. Viele führen als Inhalt eine feinkörnige gelbe Masse, die das ganze Lumen ausfüllt.

Ziemlich reichlich ist das Holzparenchym in das Libriform eingesprengt. Es ist unregelmäßig konturiert, mit gelbbraunem Inhalt gefüllt und dünnwandig. Man findet es einzeln zerstreut oder in kurzen tangentialen Reihen. Es kommen schmale konzentrische Ringe vor, in denen sich das Holzparenchym stark häuft und die in diesem Ringe liegenden zahlreichen Gefäße meist einschichtig umkränzt. Seine Wände sind zart und einfach getüpfelt.

Die Gefäße, deren Anzahl und Größe im Holz nicht bedeutend variiert, stehen selten isoliert; häufig findet man sie in radialen zu 2-7, hie und da auch in regellosen Gruppen bis zu 8. Das Lumen übersteigt nicht $130 \mu$ im größten 
Durchmesser. Auf dem Querschnitt zeigt sich als Inhalt ein mehr oder weniger dicker Wandbelag von harziger Konsistenz. Die Gefäßglieder sind kurz, die einfach und rund perforierten Scheidewände steil geneigt, sodaß die Glieder in scharfer, seitlich verschobener Spitze enden. Der nicht resorbierte Teil der Scheidewand ist äußerst reichlich hofgetüpfelt. Die Gefäßwände führen sehr dicht gestellte Hoftüpfel mit kreisrundem oder schwach ovalem, $5 \mu$ großem Hof und schmaler, spaltenförmiger Mündung, die den Hofdurchmesser an Länge nicht erreicht. Bei einander anlagernden Wänden kreuzen sich die Tüpfel. Bei Berührung mit Markstrahlparenchym findet keine Änderung der GefäBtüpfelung statt.

Die Markstrahlen erscheinen auf dem Querschnitt meist einreihig. Die Zellen sind mehr oder weniger radial gestreckt. Auf dem Tangentialschnitt sind die Markstrahlen 1-3 reihig (meist einreihig) und bis 23 Zellen hoch. Die einzelnen Zellen sind rundlich oder etwas langgestreckt. Die Kante bildet eine meist nicht lange Reihe achsial gestreckter »stehender " Zellen, deren letzte stets spitz ist. Dem Radialschnitt zufolge sind die Markstrahlen in der Mitte fast nur aus »liegenden " Zellen zusammengesetzt, deren radiale Länge das sechsfache ihrer Höhe beträgt. Die »stehenden " Zellen sind um das Vierfache ihrer Breite achsial gestreckt. Die Wände beiderlei Zellen sind gleich dick und einfach, reichlich perforiert. Die »liegenden « Zellen bilden radial verlaufende Interzellularen. Bei Berührung mit Gefäßen sind die Radialwände der »stehenden " Zellen ebenso reich getüpfelt als die anliegende Gefäßwand, sodaß jedem Gefäßhoftüpfel ein Markstrahltüpfel entspricht.

Urophyllum callicarpoides. K. Sch. var. glabrata. Jaunde-Kamerun. leg. Zenker. 812.

Cinchonoideae. Gardeniinae. Mussaendeae.

Das äußerst leichte, hellfarbige Achsenstück besitzt einen Durchmesser von $2^{1} / 2 \mathrm{~cm}$ und eine glatte, sehr dünne Rinde. 
Das Mark ist ausgehöhlt bis auf einen pergamentartigen, silbern glänzenden Wandbelag. In diesem finden sich unzählige Kristallnädelchen in zusammengeschrumpften Zellen. Jahrringbildungen und Markstrahlen sind nicht wahrnehmbar, die Gefäßlumina dagegen deutlich kenntlich.

Die mikroskopische Untersuchung zeigt, daß Jahrringbildungen nicht vorhanden sind. Alle das Holz zusammensetzenden Elemente zeigen keine periodisch wiederkehrenden Veränderungen, sondern sind gleichmäßig über den Querschnitt zerstreut.

An der Bildung des Holzes beteiligt sich quantitativ am stärksten das Libriform. Es steht in schön radialer Anordnung und hat unregelmäßig polyedrischen Querschnitt. Das Lumen ist durchschnittlich kleiner $(10-11 \mu)$, die Wand etwas stärker $(7,8 \mu)$ als bei Mussaenda. Die Libriformfasern zeigen sparsame Hoftüpfelung und führen keinen Inhalt. Der Tüpfelhof ist kreisrund und $3,9 \mu$ groß, die Mündung spaltenförmig, der Faserachse fast parallel gestellt und länger als der Hofdurchmesser. In benachbarten Zellen kreuzen sich die Tüpfel.

Die Gefäße haben dieselbe Anordnung wie bei Mussaenda tenuiflora. Sie stehen öfter einzeln, meist zu 2 und 3 bis 9 , in radialer Reihe oder in gruppenweiser Zusammenstellung. Ihr Umriß ist bei Gruppen- oder Reihenbildung höchst unregelmäßig, bei Einzelstellung rundlich. Das größte gemessene Gefäß zeigt $85 \mu$ Durchmesser. Die Gefäßglieder sind kurz, bald scharf, bald weniger scharf zugespitzt, jenachdem die Scheidewand steil oder schwach geneigt steht. Die Perforation ist einfach, rund oder elliptisch. Wie bei Mussaenda findet sich auf der Scheidewand auch reiche Hoftüpfelung. Die Längswände erscheinen äußerst zahlreich hofgetüpfelt. Die Tüpfel stehen in nicht steiler linksläufiger Spirale, haben 5 ". großen kreisrunden Hof und schiefgestellte spaltenförmige Mündung. Der Spalt ist etwas kleiner als der Hof. Vereinzelt finden sich neben den Gefäßen auch gefäßähnliche Tracheiden, die spärlich hofgetüpfelt sind, deren Hof horizontal-oval ist 
und spaltenförmige der Längsachse parallele Mündung besitzt. Dieser Spalt ist dem Hofdurchmesser an Länge gleich.

Das Parenchym ist spärlich vertreten, steht meist einzeln, selten in kurzen tangentialen Reihen. Es ist dünnwandig und führt gelben Inhalt. Die Wände sind zart und sparsam getüpfelt.

Die Markstrahlen zeigen sich auf dem Querschnitt größtenteils einreihig. Auf dem Tangentialschnitt findet man denselben Typus wie bei Mussaenda tenuiflora. Doch werden? die Markstrahlen bis 4 Zellen breit. Die »liegenden « Zellen haben nicht so bedeutende radiale Streckung, dafür etwas größere Höhe. Der Bau der »stehenden « Zellen, die Tüpfelung bei Berührung mit Gefäßwänden und untereinander sowie die Wandstärke läßt keine Unterschiede erkennen.

Sabicea calycina. Benth. Bipinde-Kamerun. leg. Zenker. 1140.

Cinchonoideae. Gardeniinae. Mussaendeae.

Zur Untersuchung liegt ein starkes Achsenstück von fast schwarzer Farbe vor. Das Holz ist relativ leicht; die als dunkle Punkte kenntlichen Gefäßlumina sind von einem tangential gestreckten, fast spindelförmigen, hellen Hof umgeben, die Markstrahlen mit freiem Auge nicht wahrnehmbar. Mehrere 1-2 $\mathrm{mm}$ breite, konzentrische, zusammenhängende gefäßlose Ringe beweisen Zuwachszonenbildung. Auf dem Längsschnitt ist das Holz schön nadelrissig gezeichnet. Die Parenchymhöfe der Gefäße erscheinen in langen schwarzen Linien. Der Radialschnitt ergibt eine deutliche Querbänderung: Die Markstrahlen zeigen sich teils dunkel, teils gelbbraun gefärbt.

Jahrringbildung ist mikroskopisch deutlich zu erkennen, da das Spätholz von einem schmalen konzentrischen Libriformring gebildet wird, in dem weder Holzparenchym noch Gefäße zu finden sind. Die Gefäße nehmen in den bedeutend breiteren Frühholzzonen nach dem Spätholz hin - jedoch nicht auffallend - an Größe ab. 


\section{$-20-$}

Das Holz ist in seinem gesamten Innern von langen dunkelbraunen Pilzfäden durchsetzt. Diese sind $5,2 \mu$ breit und besonders reichlich in den Holzparenchymzellen vorhanden, wo sie in dichtem Knäuel die ganze Zelle anfüllen. Allein diese Pilzanhäufung in den Parenchymzellen bedingt die makroskopisch wahrnehmbare schwarze Liniierung des Längsschnittes. Jede radiale Zellreihe der Markstrahlen wird von einem Pilzfaden durchzogen. Oft anastomosieren 2 solche Fäden durch ein Verbindungsstück, das seinen Weg durch einen Tüpfelkanal gefunden hat. Aus dem Holzparenchym gelangen die Fäden ebenfalls durch die Tüpfelkanäle in die Gefäße, wo sie sich in geringerer Anzahl den Längswänden eng anlegen. Den Inhaltsstoffen des Parenchyms und der Markstrahlzellen und der Färbung der Zellmembranen zufolge würde das Holz ohne Pilze helle oder gelbliche Farbe besitzen.

Das Libriform ist auf dem Querschnitt sehr regellos geordnet und kreisrund bis scharfeckig-polyedrisch konturiert. Das Lumen ist punktförmig bis $5,5 \mu$ groß, die Wand $5,2 \mu$ dick. Diese ist von sehr wenigen und sehr kleinen nicht hofgetüpfelten, rund bis oval geformten Kanälen durchbrochen, die in einer der Längsachse parallelen Reihe stehen. Die Fasern sind sehr lang und scharf zugespitzt.

Holzparenchym umgibt die Gefäße allseitig und setzt sich immer in mehreren Reihen tangential fort; teils verbinden diese Parenchymbinden mehrere Gefäße untereinander (oft im inneren Teil der Frühholzzone), teils enden sie blind im Libriform. Der Zellenquerschnitt ist höchst unregelmäßig eckig. Auf dem Längsschnitt zeigt sich das Holzparenchym als kurze achsial gestreckte, teils zugespitzte, teils prismatische Zellen, deren dünne Wände spärlich, einfach und zart getüpfelt sind. Bei Berührung mit der Gefäßwand korrespondiert mit jedem Gefäßhoftüpfel ein etwas kleinerer, einfacher Holzparenchymtüpfel. Als Inhalt führt das Holzparenchym eine zitronengelbe harzige Masse in geringen Mengen. 
Die Gefäße stehen auf dem Querschnitt meist einzeln, z. T. zu Paaren, selten zu dreien zusammen. Bei Einzelstellung ist ihr Umriß kreisrund, hie und da wenig radial gestreckt. Das Lumen erreicht eine Größe von $190 \mu$, die Wand ist $7,8 \mu$ dick und von einer sehr großen Anzahl linksspiralig aufsteigender Hoftüpfel durchbrochen. Ihr Hof ist elliptisch und 5,5 $\mu$ groß, ihre Mündung spaltförmig; der Spalt schmal, horizontal gestellt und von Hofdurchmessergröße oder kleiner. Die Gefäßglieder sind sehr kurz und von horizontalen Scheidewänden begrenzt, die einfache, runde Perforation zeigen. Einige Gefäße zeichnen sich auch durch engstehende, netzförmige Verdickungsleisten aus.

Wie alle vorhergehenden Elemente abweichend von Mussaenda und Urophyllum gebaut sind, so auch die Markstrahlen. Auf dem Querschnitt erscheinen sie selten ein-, meist zweireihig. Die Zellen sind alle radial gestreckt. Auf dem Tangentialschnitt ergeben die Markstrahlen spindelförmigen Anblick mit abgerundeter Spitze. Die einreihigen Markstrahlen werden 13 Zellen, die mehrreihigen höchstens 20 Zellen hoch. Außer den beiden letzten Kantenzellen, die stets spitz enden, zeigen alle übrigen rundlichen Querschnitt (Tangentialschnitt). Wie der Radialschnitt beweist, sind die Markstrahlen ausschließlich aus »liegenden « Zellen zusammengesetzt, deren radiale Länge das $4-5$ fache ihrer Höhe beträgt. In den Zellen lagert in großen Massen derselbe gelbe Inhalt, der in den Gefäßen und im Parenchym zu finden ist. Ausnahmslos durchzieht jede Zellreihe mindestens ein Pilzfaden. Zwischen den Zellen verlaufen in radialer Richtung ziemlich große Interzellularen. Die Tüpfelung der Wände ist sparsam und klein.

Außer diesen 4 Elementen beteiligen sich noch Kristallkammerfasern am Aufbau des Holzes. Sie kommen in großer Anzahl und Länge ausschließlich an॰der Grenze der Parenchymbänder vor. Nie finden sie sich im Libriform oder in den Parenchymbinden eingelagert. Sie führen große rhombische Einzelkristalle aus oxalsaurem Kalk. 


\section{Chomelia grandiflora. Hiern.}

leg. Zenker. 1640. Bipinde-Kamerun.

Cinchonoideae. Gardeninae. Gardenieae.

Das untersuchte Achsenstück hat einen Durchmesser von $3 \mathrm{~cm}$ und ein Mark von 0,6 cm Dicke. Das Holz ist relativ reicht und hell gefärbt. Die Zuwachszonen sind bei makroskopischer Betrachtung nicht erkennbar. Man sieht die Gefäße als dunkle Punkte von einem tangential gestreckten, hellen Hof umgeben. Bei Betrachtung mit freiem Auge scheinen diese Höfe zusammenzufließen und wellige, konzentrische feine Ringe zu bilden. Die Markstrahlen sind unkenntlich.

Libriformfasern bilden die Grundmasse bes Holzkörpers. Auf dem Querschnitt sind sie im allgemeinen tangential gestreckt, am stärksten in den Reihen, die die Markstrahlen begleiten (Lumenverhältnis $10: 7 \mu$ ). Während die relativ kurzen Libriformfasern im inneren Teil der Zuwachszone in regelrechter, radialer Anordnung stehen, geht diese in den Schichten des Spätholzes verloren. Sie verkleinern in der Spätholzzone ihren Querschnitt, verdicken ihre Membran und nehmen durch die stärkere Zusammenpressung unregelmäßig-polygonale Querschnittsfläche an. Die Wandstärke schwankt zwischen 2,6 und $3,4 \mu$. In der Mitte vieler Holzstränge liegen oft kurze Reihen von Libriformfasern mit recht kleinem polyedrischen Querschnitt eingepreßt, deren Lumen punktförmig geworden ist. Die Libriformfasern laufen in eine sehr lange, scharfe Spitze aus. Irgend welche Gabelung der Fasern und Färbung ihrer Membran findet nicht statt. Erst nach mühsamem Suchen findet man ganz vereinzelte, sehr kleine, steil gestellte Spaltentüpfel.

Außer dem Libriform nehmen noch die Gefäße Anteil an der Markierung der Jahrringgrenzen. Das Frühholz beginnt mit einem konzentrischen Ring großer Gefäße. Diese werden durch Parenchym lückenlos miteinander verbunden, 
sodaß sich die Grenze zwischen Früh- und Spätholz mikroskopisch scharf abhebt. Diese Jahrringgrenze wird noch dadurch hervorgehoben, daß die Gefäße im Spätholz durch ihre geringere Größe und Anzahl sehr gut von denen des Frühholzes zu unterscheiden sind. - Die Gefäße sind durchschnittlich sehr groß (bis $155 \mu$ Durchmesser), dünnwandig und stehen isoliert oder $\mathrm{zu} 2-4$ in radialer Zusammenstellung, meist zu Paaren. Sie werden wegen ihrer Größe sehr oft von Markstrahlen berührt. Sie sind von Thyllen vollgepfropft. Sind keine Thyllen vorhanden, so führen die Gefäße keinen Inhalt. Ihre Längswände sind von zahlreichen, in linksspiraliger Anordnung stehenden, ovalen Tüpfeln mit rundem, 6 " großem Hof besetzt. Die Scheidewände sind schwach geneigt und fast ganz resorbiert: Die Durchbrechung ist demnach einfach lochartig.

Auf dem Querschnitt ist die Gruppierung des Parenchyms schon makroskopisch erkennbar. Ausnahmslos wird jedes Gefäß ringsum von Parenchym umschlossen, das sich in tangentialer Richtung nach beiden Seiten hin in spindelförmiger Verjüngung fortsetzt. Die Parenchymbinden hängen nur im oben angegebenen ersten Gefäßring des Frühholzes kontinuierlich zusammen, im übrigen Teil der Zuwachszone nur bei 2 oder 3 nahestehenden Gefäßen. Das Parenchym ist sehr dünnwandig, breit und kurz. Bei gegenseitiger Anlagerung und bei Berührung mit Libriform sind die Wände sparsam und fein perforiert; nur die den Gefäßen angrenzenden Wände sind von zahlreichen einfachen, $4,5-5 \mu$ großen, kreisrunden Tüpfelkanälen durchbrochen.

Eigenartig sind die Markstrahlen gebaut. Die bei den Rubiaceen auf dem Tangentialschnitt allgemein beobachtete spitz-spindelförmige Umgrenzung des Markstrahls erfährt hier eine Abänderung. Während sonst die äußerste Kante des Markstrahls stets von einer mehr oder weniger achsial gestreckten, meist zugespitzten Zelle gebildet wird, findet man an den Enden der Markstrahlen von Chomelia grandiflora 
eine kaum von den übrigen zu unterscheidende rundliche Zelle, ja oft sogar 2 nebeneinander liegende Zellen, sodaß das Markstrahlende abgeplattet erscheint. Nur ganz vereinzelt finden sich Markstrahlen, deren oberste Kantenzelle durch sehr geringe Verlängerung auffällt. Auch unter den übrigen Zellen kann man kaum einen Größenunterschied beobachten. Die Markstrahlen sind 1-2reihig und ungleich hoch; ihre vertikale Ausdehnung schwankt zwischen 3-20 Zellen. Wie der Radialschnitt zeigt, bestehen die meisten Markstrahlen fast nur aus radial bedeutend gestreckten Zellen, die gelbbraunen Inhalt führen. Hin und wieder führt ein Markstrahl höchstens 2 Reihen von quadratischen oder wenig achsial gestreckten Zellen, die man aber nicht als »stehende « Zellen bezeichnen kann, da zwischen ihnen, wie zwischen den »liegenden« Zellen, deutlich wahrnehmbare Interzellularen verlaufen. Auf dem Querschnitt sieht man sehr schön, wie die Horizontalwände nur 2 Tüpfelreihen führen, deren Tüpfelkanäle in die Interzellularen münden. Die Tüpfelung der übrigen Wände ist gewöhnlich.

\title{
Chomelia nigrescens (Hook fil.) K. Sch.
}

\author{
leg. Holst. 3562. Usambara.
}

Cinchonoideae. Gardeninae. Gardenieae.

Im Gegensatz zu Chomelia grandiflora ist dieses $\mathrm{Holz}$ äußerst hart und sehr schwer. Nach Wiesner, p. 141 (Rohstoffe des Pflanzenreichs) tritt der Baum im Gebiet des Kilomandscharo und bei Usambara auf und liefert ein hellgelbes, bräunlich gezontes, wertvolles, vielseitig verwendbares Nutzholz. Znwachszonen sind in großer Anzahl sehr deutlich sichtbar. Das ältere Holz ist heller gefärbt als das jüngere. Markstrahlen und Gefäßporen sind unkenntlich. Bei Lupenbetrachtung sind nur die Gefäßporén schwach sichtbar.

Jahrringbildungen werden markiert durch Unterschiede in der Anzahl und Größe der Gefäße, durch etwas stärkere 
Verdickung nebst tangentialer Streckung des Libriforms und durch fast unmerkliche radiale Verkürzung der Markstrahlzellen im äußeren Ringteil. Das Frühholz beginnt mit einem deutlichen konzentrischen Ring größerer Gefäße, die nach dem Spätholz hin mehr und mehr an Größe und Zahl abnehmen, um in den letzten 5-8 Libriformschichten des Spätholzes nur äußerst selten aufzutreten.

Die Grundmasse des Holzes wird vom Libriform gebildet. Es ist radial angeordnet, besitzt meist runden oder unregelmäßig polyedrischen Querschnitt und oft punktförmiges Lumen. Die Wand ist 7-8 $\mu$ dick, gelblich gefärbt und mit spaltenförmigen, in vertikalen Reihen übereinanderstehenden Hoftüpfelı spärlich versehen. Der Hof ist $3 \mu$ groß, die Mündung spaltförmig, ein wenig kleiner als der Hof und der Längsachse der Faser fast parallel gestellt. Eine harzige Inhaltsmasse füllt entweder das Lumen ganz aus oder liegt in gelben Tröpfchen darin. Die Fasern sind sehr lang und enden teils in scharfer, langer Spitze, teils bajonettartig.

Die Gefäße sind in der bei der Jahrringbildung angegebenen Weise gruppiert. Sie sind äußerst zahlreich vorhanden und lagern meist einzeln, im Frühholz hie und da in radialen Reihen zu 2-3. Ihr Umriß ist kreisrund oder elliptisch, ihr Lumen nicht über $31 \mu$ weit. Die Seitenwände sind sehr stark verdickt und zeigen in steil-spiraliger Anordnung wenig runde oder elliptische Hoftüpfel mit $5 \mu$ großem Hof und sehr kleinem Spalt. Die Gefäßglieder werden von horizontalen oder schwach geneigten Scheidewänden begrenzt, die einfach und kreisrund durchbrochen sind. Entweder sind die Lumina streckenweise mit einer gelben, harzigen Masse vollgepfropft (hauptsächlich im älteren Holz) oder es lagern große Tropfen dieser Substanz darin (im jüngeren Holz). Bei Berührung mit Libriform korrespondiert mit jedem Libriformtüpfel ein Gefäßtüpfel.

Das Holzparenchym steht so vereinzelt, daß es erst nach längerem Suchen zu finden ist. Es zeigt die gewöhn- 
liche prismatische Form und ist mit dem schon in den übrigen Elementen gefundenen tröpfchenförmigem Inhalt gefüllt. Die Tüpfelung ist reichlich, rund und einfach.

Die Markstrahlen sind spitz-spindelförmig, zu $80 \%$ einreihig, sonst zwei-, sehr selten dreireihig. Die einreihigen werden bis 7 , die mehrreihigen bis 21 Zellen hoch. Der mittlere Teil des mehrreihigen Markstrahls besteht nur aus »liegenden «, die Kanten, wie auch die einreihigen Markstrahlen, nur aus »stehenden " Zellen. Die letzte Kantenzelle ist stets spitz. Auf dem Radialschnitt ist die radiale Streckung der »liegenden " Zellen nicht bedeutend, die achsiale der "stehenden Z Zellen das Dreifache ihrer Breite. Einige Reihen zwischen den »liegenden " Zellreihen setzen sich aus isodiametrischen Zellreihen zusammen. Die Wände der »stehenden « Zellen sind etwas stärker als die der liegenden, beide einfach und reichlich getüpfelt. Der harzige Inhalt findet sich in Tröpfchen vor.

\section{Oxyanthus speciosus P. D. C. leg. Mismahl. 7. Usambara.}

Cinchonoideae. Gardeninae. Gardenieae.

Auf dem Querschnitt des unserem Edeltannenholz ähnlich gefärbten, ziemlich leichten Holzes sind Zuwachśzonen sehr deutlich sichtbar. Schmale dunkle Ringe heben sich vom helleren Grunde in Abständen von 1-2 mm sehr gut ab. Das Holz wird von Mismahl mit dem Vulgärnamen "msala gutes Bauholz « bezeichnet. Die großen Gefäßporen sind mit freiem Auge als helle Punkte, die Markstrahlen als äußerst feine, weiße wellige Linien kenntlich. Die Markstrahlen weichen den Gefäßen aus.

Mikroskopisch sind die Grenzen zwischen Spät- und Frühholz deutlich gekennzeichnet, da die Spätholzzone durch mehr oder weniger breite parenchym- und gefäßarme konzentrische Libriformringe gebildet wird, deren Elemente eng- 
lumig und dickwandig sind und etwas radiale Verkürzung erfahren. Die Markstrahlzellen schließen sich der Ringbildung insofern an, daß sie in den letzten Spätholzschichten wenig tangentiale Verbreiterung zeigen. Typische Unterschiede der Gefäßbildung und Gefäßanordnung im Früh- und Spätholz sind nicht zu erkennen, sodaß eine scharfe Abgrenzung der einzelnen Jahrringe nicht vorhanden ist.

Das Libriform bildet die Grundmasse des Holzes, zeigt streng radiale Anordnung - besonders im Spätholz - , hat rundlichen oder tangential gestreckten, reckteckigen Querschnitt und läßt oft deutlich die 3 Verdickungsmembranen der Wand erkennen. Von diesen zeigt die sekundäre oft radiäre Faltung. Bei Zusammentreten von 3 oder 4 Libriformfasern entstehen dreieckige Zwickel. Die Wand ist 5 bis $5,5 "$ "dick und gelb gefärbt, das Lumen rund und $4-6 "$ " groß. Die gelbe Membranfärbung geht bei längerem Liegen in Wasser verloren. Die spärlich vorhandenen Hoftüpfel haben einen kleinen kreisrunden Hof und 5,4 $\mu$ lange, der Faserachse parallel gestellte, spaltförmige Mündung, die den Hof an Länge überragt. Bei Angrenzung an Holzparenchym korrespondiert mit jedem Faserhoftüpfel eine einfache, runde Perforation der Parenchymwand.

Das Holzparenchym ist ziemlich reichlich vertreten, dünnwandig, unregelmäßig konturiert und $25-27 \mu$ weit. . Es bildet ein- oder zweireihige, tangentiale Ketten, die ebenso oft in Berührung mit Gefäßen stehen, als sie zwischen ihnen frei verlaufen. Diese Ketten sind 3-10 Libriformschichten voneinander entfernt und umgeben bei Konnex mit Gefäßen diese immer nur auf einer Seite mit einer einzigen Schicht. Sehr selten findet sich alleinstehendes Parenchym. Die Ketten sind auf dem Querschnitt gewellt und oft durch eine schief verlaufende kurze Parenchymreihe miteinander verbunden. Die Wände sind schwach porös getüpfelt. Bei Angrenzung an Gefäßwände zeigen sich horizontal-langgezogene, ziemlich 


\section{$-28-$}

breite einfache Tüpfel. Als Inhalt finden sich viele helle ÖItropfen.

Die Gefäße sind sehr dünnwandig und haben elliptischen Querschnitt mit durchschnittlich $130 \mu$ langer, radial gerichteter Achse. Sie lagern vereinzelt und gruppenweise; die Gruppen fast immer aus 2--4, vorwiegend aus 3 radial oder in anderer Richtung aneinandergereihten Gefäßen bestehend. Auf dem Querschnitt grenzen die Gefäße sehr oft auf einer, bisweilen auch auf beiden radialen Seiten an Markstrahlen. Ihre Wände werden spärlich von länglich runden Hoftüpfeln durchbrochen, deren schwach schief gestellte Mündung elliptisch ist und nicht über den Hof hinausgeht. Der Hof hat $7.8 \mu$ Durchmesser, der Spalt 5,2 $u$ Länge. Charakteristisch ist die Art der Kommunikation mit den »stehenden "Markstrahlzellen. Hier zeigt sich ihre Wand wenigspangig, leiterförmig perforiert. Bei Berührung mit den »liegenden « Markstrahlzellen, wie auch mit dem Holzparenchym, lassen die Gefäße alle Übergänge zwischen Tüpfeln mit rundem, großem Hof und spaltenförmiger Mündung und außerordentlich langgestreckten, beinahe unbehöften erkennen. Die Gefäßscheidewände sind schwach geneigt und zeigen in der Mitte in Form eines großen, rundlichen oder ovalen Loches die Perforation. Bei Anlagerung an Libriform kreuzen sich die Tüpfelspalten beider Elemente. Bisweilen findet schwache Thyllenbildung statt.

An der Zusammensetzung der auf dem Tangentialschnitt langgezogenen, bis 35 Zellen hoch und 4 Zellreihen breit werdenden Markstrahlen nehmen "liegende " und »stehende" Zellen teil. Die Verteilung dieser beiden Zellenarten findet so statt, daß die »liegenden " in Verbindung mit einigen eingeschalteten Reihen von achsial unmerklich gestreckten Zellen den mittleren Teil einnehmen, während die »stehenden « an der Kante ausgebildet sind und hier eine mehr oder weniger hohe Reihe sehr langgestreckter Zellen bilden, die oft eine Verbindung zwischen 2 Markstrahlen herstellt. Die einreihigen 
Markstrahlen bestehen nur aus »stehenden « Zellen. In sämtlichen »stehenden « Zellen befinden sich im Gegensatz zu den »liegenden « viele glashelle Öltröpfchen, in wenigen außerdem noch ein feinkörniger, gelblicher Niederschlag. Die Wände beider Zellarten sind $4 \mu$ stark nnd ziemlich spärlich, einfach durchbrochen. Die Interzellularen zwischen den »liegenden « Zellen sind sehr zart, die einzelnen Markstrahlen seitlich durch 2-10, allgemein 5 Libriformschichten, von einander getrennt.

\section{Oxyanthus unilocularis. Hiern.}

\section{leg. Zenker. 1584. Bipinde-Kamerun.}

Cinchonoideae. Gardeninae. Gardenieae.

Als Einzelheiten sieht man auf dem Querschnitt mit freiem Auge nur die sehr eng und äußerst zart verlaufenden, hellen Markstrahlen und einige größere, regellos liegende, helle Komplexe sich von dem dunklen Grunde abheben. Jahrringe und Gefäßporen sind nicht wahrnehmbar; bei Lupenbetrachtung tauchen die Gefäße als zahllreiche kleine, zerstreut liegende helle Punkte auf. Die Farbe und Schwere ist dieselbe wie die von Oxyanthus speciosus.

Mikroskopisch sind keine Zuwachszonen festzustellen.

Anordnung, Form und Färbung des Libriforms ist dieselbe wie bei Oxyanthus speciosus. Jedoch bildet die vorliegende Art keine Zwickel und besitzt bei derselben Wandstärke ein durchschnittlich dreifaches Lumen. Die Längswände sind im Verhältnis zu Oxy. spec. von äußerst zahlreichen Hoftüpfeln durchbrochen, die reihenweise übereinanderstehen, kreisrunden $3 \mu$ großen Hof und spaltenförmige, der Längsachse der Libriformfaser fast parallel gestellte Mündung von Hofdurchmessergröße besitzen. Bei gegenseitiger Anlagerung kreuzen sich die Tüpfel. Die Fasern sind sehr lang und enden in scharfer Spitze.

Die Gefäße sind bedeutend zahlreicher und kleiner als bei Oxy. spec. und werden fast immer auf beiden radialen 
Seiten von Markstrahlen berührt. Sie stehen zum weitaus überwiegenden Teil einzeln, selten zu Paaren und haben unregelmäßig eckigen Umriß. Die Wand ist sehr dünn und von eng aneinander gestellten Hoftüpfeln durchbrochen. Diese stehen in linksläufiger Spirale; ihr Hof ist oval oder kreisrund, $3,2 \mu$ groß, ihre Mündung spaltförmig, schwach schief gestellt und kleiner als der Hofdurchmesser. Die Gefäßglieder sind seitlich scharf zugespitzt und von steil gestellten Scheidewänden begrenzt, die entweder seitlich oder in der Mitte ein großes, kreisrundes bis elliptisches Loch als Perforation zeigen. Der nicht resorbierte Teil der Scheidewand trägt dieselben Hoftüpfel wie die Gefäßwand.

Neben den Gefäßen kommen auch lange Gefäßstracheiden vor, die sich durch die Art ihrer Tüpfelung von den Gefäßen unterscheiden. Die spärlichen Hoftüpfel besitzen kreisrunden, $5,2 \mu$ großen Hof und spaltförmige, der Längsachse fast parallele Mündung.

Was das Parenchym betrifft, so finden sich erhebliche Unterschiede von Oxy. spec. nur in der Anordnung. Es steht bei Oxyanthus unilocularis nie in Ketten, sondern stets einzeln. Sein Lumen ist höchstens halb so groß als bei Oxy. spec. Tüpfelung und Form wie gewöhnlich, d.h. erstere ist zart porös, letztere prismatisch, dünnwandig.

Die Markstrahlen zeigen ähnlichen Bau wie Oxy. spec. Sie sind 1-4 reihig, vorwiegend zweireihig, bis 25 Zellen hoch und auf den Tangentialschnitt langspindelförmig. Bei den mehrreihigen Markstrahlen wird jedoch der mittlere Teil fast ausschließlich aus Reihen von isodiametrisch gebauten Zellen zusammengesetzt. Nur vereinzelte Reihèn bestehen und diese auch nur streckenweise - aus radial stärker gestreckten Zellen. Es findet sich also das umgekehrte Verhältnis wie bei Oxy. spec. Die Kanten bilden auch hier eine einzige lange Reihe von »stehenden Zellen, die hie und da 2 Markstrahlen miteinander verbinden kann. Die einreihigen Markstrahlen bestehen nur aus »stehenden« Zellen. Beiderlei 
Zellen sind sehr zart, einfach und reichlich getüpfelt, besonders die Zellwände, die an Gefäßwänden vorüberführen. Hier korrespondiert mit jedem Gefäßhoftüpfel ein einfacher, ebenso großer Markstrahltüpfel. Als Inhalt findet sich in vielen Zellen eine feinkörnige oder tröpfchenförmige Masse, die sich bei Behandlung mit Kupferacetat und Eisenchlorid dunkel färbt, also gerbsäurehaltig išt. Im mittleren Teil sind die radial verlaufenden Interzellularen äußerst zart.

\title{
Gardenia ramentacea. K. Sch.
}

\author{
leg. Zenker. 1147. Kamerun.
}

Cinchonoideae. Gardeninae. Gardenieae.

Zur Untersuchung liegt ein Stammstück von $5 \mathrm{~cm}$ Durchmesser vor. Das Holz hat schwefelgelben Grundton und besitzt ein $1,3 \mathrm{~cm}$ starkes, rostbraunes Mark mit größeren, gelben Flecken. Jahrringe sind nicht sichtbar, die Markstrahlen als helle gelbliche, sehr feine radiale Streifung, Gefäße als dunkle Punkte kenntlich. Das Achsenstück ist von $0,4-1,4 \mathrm{~cm}$ dicken Larvengängen durchsetzt. Auf der Radialfläche hat das $\mathrm{Holz}$ metallischen Glanz; die Markstrahlen erscheinen hier als breite rotbraune Linie.

Mikroskopisch zeigt kein Element irgend welche periodische Änderung in Größe, Anzahl und Anordnung. Das Holz ist höchst gleichmäßig gebaut.

Das Libriform bildet die Grundmasse des Holzkörpers. Es ist streng radial geordnet und zeigt sehr kleinen, fast immer tangential gestreckten Querschnitt. Die Wände sind 2,5-2,7 $\mu$ dick und stellenweise intensiv gelb gefärbt, sodaß der Querschnitt des Stammes ein fleckiges Aussehen hat. Das Lumen ist im Verhältnis zur Wandstärke groß. Die Wände sind von so schmalen, langen spaltenförmigen Tüpfeln durchbrochen, daß sie auf dem Querschnitt nicht festzustellen sind. Die Tüpfel sind unbehöft. Bei gegenseitiger Anlagerung 
zweier Libriformfasern kreuzen sich die Tüpfel. Die Fasern enden in langer, scharfer Spitze und führen keinen Inhalt.

Die äußerst zahlreichen Gefäße sind gleichmäßig über den Querschnitt zerstreut. Sie lagern einzeln oder in Gruppen zu 2-7 in radialer, hie und da auch in regelloser Anordnung. Liegen sie einzeln, so ist ihr Umriß kreisrund oder elliptisch, sonst entsprechend abgeplattet. In der nächsten Umgebung des Markes finden sich nur sehr wenige und kleine Gefäße. Die Wand ist sehr dünn, gelb gefärbt und fast immer auf beiden radialen Seiten von Markstrahlen berührt. Sie führt in großer Anzahl linksspiralig aufsteigende Hoftüpfel, deren Hof elliptisch, fast horizontal gestellt und $7,8-8 \mu$ groß, deren Mündung spaltförmig, schmal und stets viel kleiner als der Hofdurchmesser ist. Die sehr langen Gefäßglieder werden von horizontalen oder schwach geneigten Scheidewänden begrenzt, deren Durchbrechung einfach, elliptisch ist. Bei Angrenzung an »stehende Markstrahlzellen ist die Gefäßwand von horizontal langgezogenen, breiten einfachen Tüpfeln durchbrochen. Oft findet sich starke Thyllenbildung und gelber, harziger Inhalt; in einigen auch Pilzhyphenknäuel.

Das Holzparenchym kommt ausschließlich in Verbindung mit Gefäßen vor. Es umgibt diese in $1-2$ Schichten, immer auf der äußeren, seltener auch auf der inneren Tangentialseite und setzt sich bisweilen, da die Gefäße fast immer auf den beiden Radialseiten von Markstrahlen berührt werden, jenseits der Markstrahlen in wenigen Zellen fort. Es ist unregelmäßig konturiert, dünnwandig und mit großen Stärkekörnern oder dem in den anderen Elementen gefundenen dunklen bis rotbraunen harzigen Inhalt vollgefüllt. Zwischen den Stärkekörnern finden sich in den Zellen, die von Pilzfäden durchwuchert werden, unter dem Mikroskop violett gefärbte kleine Tröpfchen, die den ganzen Zellinhalt bei schwacher Vergrößerung dunkel erscheinen lassen. Die Tüpfelung ist einfach und reich porös. 
Die Markstrahlen sind ein- und zweireihig, vorwiegend einreihig, auf dem Tangentialschnitt spindelförmig und zum größten Teil (die einreihigen stets) aus achsial gestreckten Zellen zusammengesetzt. Der Radialschnitt zeigt, daß der mittlere Teil aus »liegenden " und "stehenden « Zellen derart zusammengesetzt ist, daß abwechselnd auf $1-4$ Reihen »liegender" Zellen eine oder zwei Reihen "stehender " folgen. Dieser Teil der Markstrahlen wird bis 8 Reihen hoch. Die hier liegenden »stehenden " Zellen sind teils achsial stark gestreckt, teils isodiametrisch. Die Kante des Markstrahls wird stets von einer einzelnen oder von einer.Reihe achsial sehr langgestreckter »stehender "Zellen gebildet. Die »liegenden « Zellen führen als Inhalt die oben angegebene Harzmasse und einzelne Stärkekörner, die »stehenden " nur Stärkekörner. Verhältnismäßig oft finden sich in den "stehenden " Zellen auch Kristalldrusen. Diese kristallführenden Zellen sind entweder unverändert geblieben oder haben sich in einzelne Teile mit je einer Druse gekammert. Die Wände der Markstrahlzellen sind düın und weisen reichliche Tüpfelung auf. Die Interzellularen zwischen den »liegenden Zellen sind äußerst zart.

\section{Heinsia diervilloides. K. Sch.}

leg. Scheffler. 38. Ostafrika-Ngnelo.

Cinchonoideae. Gardeninae. Gardenieae.

Das zu untersuchende Achsenstück hat $4 \mathrm{~cm}$ im Durchmesser, ist leicht und von heller Farbe. Helle und dunkle Ringzeichnungen wechseln deutlich sichtbar miteinander ab. Außerdem sind noch einige kürzere helle Streifen und Flecke zu erkennen. Nur die breiteren Markstrahlen sind makroskopisch schwach kenntlich, die Gefäßporen unkenntlich. Unter der Lupe sind noch zahlreiche schmale Markstrahlen als helle Linien wahrnehmbar.

Mikroskopisch sind zahlreiche tangentiale Binden festzustellen, die aber nicht kontinuierlich zusammenhängen, sondner 
auf kurze Strecken hin Unterbrechungen erleiden. Sie werden von Holzparenchym gebildet und verlaufen in regellosen $\mathrm{Ab}$ ständen voneinander. Zuwachszonen sind dadurch $\mathrm{zu}$ erkennen, daß das erste Frühholz unerheblich mehr und größere Gefäße enthält als das Spätholz und dieses stets viel Holzparenchym führt, das Frühholz dagegen fast frei davon ist. Die Grenze zwischen zwei Zuwachszonen bilden nur wenige Schichten radial verkürzter und etwas stärker verdickter Libriformzellen. Die Markstrahlzellen nehmen sehr wenig Anteil an dieser radialen Verkürzung, sind aber sämtlich wie auch das Holzparenchym im Spätholz mit intensiv gelbbraunem, harzigem Inhalt ausgefüllt. Die hellen, regellos zerstreuten, makroskopisch sichtbaren Flecke werden von allen Elementen gebildet. Diese sind in ihrer normalen Lagerung gestört und ausschließlich mit harzigem Inhalt vollgepfropft. Die Markstrahlen sind durch diese Flecken hindurch nicht zu verfolgen.

Die Grundmasse des Holzes wird vom radial angeordneten Libriform gebildet. Sein Zellenquerschnitt ist rundlich oder unregelmäßig polyedrisch, sein Lumen stets rundlich. Die Wand ist $5,5 \mu$ dick, schwach gelblich gefärbt und von Hoftüpfeln durchbrochen, deren kreisrunder Hof $2,7 \mu$ groß, deren Mündung sehr schmal, spaltförmig ist und der Längsachse fast parallel steht. Die Tüpfel stehen in vertikaler Reihe übereinander; der Spalt hat Hofdurchmessergröße. Bei Angrenzung der Faser an eine Gefäßwand korrespondiert mit jedem Libriformtüpfel ein Gefäßtüpfel. Als Inhalt finden sich helle Öltropfen.

Das Holzparenchym ist reichlich vorhanden und steht in keiner Beziehung zu den Gefäßen. Es ist in kurzen, meist einreihigen tangentialen Ketten in das Libriform eingesprengt oder steht isoliert. Wie schon bemerkt wurde, ist es im äußeren Teil der Zuwachszone reichlicher als im Frühholz und führt dort stets braunen Inhalt. Seine Wand ist sehr dünn und äußerst fein porös getüpfelt. Bei Anlagerung an eine Gefäßwand ist die Tüpfelung reichlicher und etwas größer. 
Die Gefäße finden sich in ungemein großer Zahl gleichmäßig auf dem Querschnitt zerstreut, isoliert oder zu Paaren. Sie haben nur bis $50 \mu$ Durchmesser und fast kreisrunden Umriß. Ihre Membran ist sehr dünn und von zahlreichen kleinen Hoftüpfeln durchbrochen, deren Hof oval und 2,6 $\mu$ groß ist und deren sehr schmale spaltförmige Mündung sich fast horizontal stellt. Die Gefäßglieder sind kurz, die Scheidewände horizontal oder nur schwach geneigt, die Perforation ist einfach, rund oder elliptisch. Inhalt führen die Gefäße nur in den krankhaften hellen Flecken des Holzes.

Auf dem Querschnitt verlaufen die Markstrahlen so zahlreicl, daß sie die kleinen Gefäße immer auf beiden Radialseiten berühren. Sie sind $1-3$ reihig und bestehen aus radial gestreckten »liegenden « und aus achsial stark verlängerten »stehenden « Zellen. Die »liegenden « Zellen setzen stets den mittleren Markstrahlteil zusammen - nie findet sich zwischen ihren Reihen eine solche »stehender « Zellen. Diese machen in mehr oder weniger langer Reihe die Kante aus. Die letzte Kantenzelle ist stets die längste und scharf zugespitzt. Zwischen den »liegenden « Zellen verlaufen ziemlich große dreieckige Interzellularen, nach denen hin (auf dem Tangentialschnitt) deutlich sichtbare Tüpfelkanäle führen. Was die Wandstärke der Markstrahlzellen betrifft, so besteht zwischen beiden Zellkategorien kein Unterschied, nur sind die Tangentialwände der an eine Gefäßwand grenzenden »stehenden « Zellen, 2-3 mal so stark als die übrigen. Die Tüpfelung ist außer der der Radialwände sehr reichlich und zart. Als Inhalt führen beiderlei Zellen Stärkekörner und die obengenannte harzige, gerbstoffhaltige Masse, viele »liegende» Zellen auch Einzelkristalle.

Heinsia pulchella (G. Don.). K. Sch.

leg. Holst. 2650. Usambara.

Cinchonoideae. Gardeninae. Gardenieae.

Zur Untersuchung liegt ein Achsenstück von $5 \mathrm{~cm}$ Durch- 


\section{$-\quad 36$}

messer vor. Das Holz ist ungemein fest, sehr schwer und scheidet sich in Kern- und Splintholz. Die 6 innersten der 8 Jahrringe, die sehr deutlich zu unterscheiden sind, bilden das schön dunkelrosa gefärbte Kernholz, die zwei äußeren das schmutzig gelbe Splintholz. Der 7. Jahrring bildet einen Übergang, da er im Frühholz auch schon schwach rosa gefärbt ist. Das Mark hat helle Farbe, ist $2^{1} / 2 \mathrm{~mm}$ stark und oval geformt. Die Gefäßporen sind deutlich alls helle Punkte, die Markstrahlen als äußerst feine radiale Streifung kenntlich. Jeder Jahrring beginnt mit einem sehr schmalen zusammenhängenden hellen Ring. Die Rinde ist schokoladenbraun, stark rissig und $2,5 \mathrm{~mm}$ dick.

Jahrringbildung ist mikroskopisch sehr gut sichtbar, denn die Abgrenzung der Zuwachszone ist scharf ausgeprägt. Das Frühholz beginnt mit großen und zahlreichen Gefäßen, mit weitlumigen und vorwiegend, im jüngsten Jahrring ausschließlich mit Inhalt gefülltem Libriform. Die Gefäße werden nach dem Spätholz hin weniger und kleiner, die Libriformfasern englumiger und dickwandiger.

Das streng radial geordnete Libriform ist innerhalb der Zuwachszone verschieden geformt; im Spätholz unregelmäßig polyedrisch, dickwandig und inhaltslos, im Frühholz tangential gestreckt, meist rechteckig mit Inhalt und Zwickelbildung. Im Kernholz ist der gefundene Inhalt rotbraun, im Splint gelbbraun. Charakteristisch ist die Fächerung und Tüpfelung des Libriforms. Die durch die zarten Querwände abgegliederten Abschnitte der bajonettartig oder gerade-spitz zulaufenden Libriformfasern sind verschieden lang. Die Wände sind mit wenigen, spaltenförmigen Hoftüpfeln versehen, deren Hof äußerst klein, deren Mündung sehr schmal ist und den Hof um das Vielfache überragt. Der Spalt liegt steil geneigt und kreuzt sich mit dem einer anliegenden Faser. Der Inhalt ist von harziger Konsistenz und färbt sich, wie auch die Inhaltsmasse der übrigen Elemente bei Behandlung mit Kupferacetat und Eisenchlorid schwarzblau. Die Rosafärbung des Kernholzes stammt hauptsächlich von der Farbe der Libriformmembranen. 
Das Holzparenchym ist sehr spärlich vertreten. Es findet sich teils einzeln an Gefäßen, teils isoliert im Libriform und ist von gewöhnlicher prismatischer Form. Es führt stets harzigen Inhalt und ist zart und sparsam getüpfelt.

Die Gefäße liegen auf dem Querschnitt isoliert oder bis zu 6 in radialen Reihen - im Frühholz herrscht Stellung zu 2 und 3, im Spätholz isolierte und paarweise vor - und haben runden Umriß bei einem Durchmesser bis $110 \mu$ und einer Wandstärke von $3,9 \mu$. Die Tüpfelung ist verschieden. Gewöhnlich finden sich zahlreiche Hoftüpfel mit schmalem Spalt, der den Hof an Länge erreicht oder über ihn hinausgeht. Die Hoftüpfel stehen in schwach geneigter linksläufiger Spirale in solcher Anzahl, daß sich die Höfe polygonal abplatten. Der Hof hat 5,2 $\mu$ Durchmesser, der Spalt ist horizontal gestellt. Grenzen 2 Gefäßwände aneinander, so kreuzen sich die Spalten. , Führt nun die Gefäßwand an Markstrahlparenchym vorbei, so finden sich alle Übergänge vom Hoftüpfel zur einfachen Perforation. Die hier auftretenden Hoftüpfel sind um das Vielfache größer als die gewöhnlichen. Dabei kommen schmale, langgezogene Spalten bei breitem, ebenso langem Hof und breiter, kurzer Spalt bei langgezogenem Hof vor oder Spalt und Hof erreichen dieselbe Größe, sodaß diese Form die einfache Perforation darstellt. Die einfache Durchbrechung ist vorwiegend und zwar kann sie wenigspangig, leiterförmig oder höchst unregelmäßig sein. Jeder Durchbrechung entspricht in der Markstrahlzelle ein ebenso großer einfacher Tüpfel. Im Kernholz wie auch im Splint sind die Gefäße der Frühholzzone von Thyllen mit rosa oder gelblichem Inhalt verstopft. Die Gefäßglieder sind ziemlich kurz, die Scheidewände schwach geneigt oder horizontal und groß, rund durchbrochen.

Der Bau der Markstrahlen ist für Heinsia pulchella charakteristisch. Sie sind zu $90 \%$ einreihig, sonst zweireihig und bis 35 Zellen hoch. Sie sind aus unterschiedslosen Zellen zusammengesetzt. Auf dem Tangentialschnitt erscheinen 
die Zellen rundlich, unmerklich achsial gestreckt; die letzte stets spitz und weniger länger als die übrigen. Auch auf dem Radialschnitt sind die Zellen nicht in »liegende « und »stehende « geschieden, sondern in der Mitte des Markstrahls meist etwas, doch sehr wenig, radial, an den Kanten unbedeutend achsial gestreckt oder isodiametrisch. Sämtliche Zellen sind mit dem in den übrigen Elementen gefundenen harzigen Inhalt ausgefüllt, doch finden sich verhältnismäßig viele Kristallzellen, in denen je ein sehr großer Einzelkristall liegt. Diese Zellen sind größtenteils inhaltslos oder schließen den Kristall in die harzige Masse ein. Die Tüpfelung der Markstrahlzellen ist außer dem bei der Beschreibung der Gefäße angegebenen Fall zart und sehr reichlich.

\section{Leptactinia enosmia.}

leg. Zenker et Staudt. 584. Jaunde-Kamerun.

Cinchonoideae. Gardeninae. Gardenieae.

Bei der makroskopischen Betrachtung des untersuchten $4^{1} / 2 \mathrm{~cm}$ dicken Achsenstückes sind nur die scharf abgegrenzten Zuwachszonen zu sehen. In ungleicher Breite wechseln dunkle und helle Ringe miteinander ab. Unter der Lupe erkennt man noch die überaus zahlreichen Gefäßporen als helle Punkte und die zarten hellen Markstrahlen. Das Holz ist weißlich gefärbt, besitzt $2 \mathrm{~mm}$ starkes braunes Mark und dunkelbraune $2 \mathrm{~mm}$ dicke Rinde.

Die einzelnen Zuwachszonen werden gebildet durch bedeutend zahlreichere, größere Gefäße neben weitlichtigerem Libriform in Frühholz und durch radiale Verkürzung der Elemente nebst Verringerung der Lumina in den letzten Schichten des Spätholzes. Die Grenze zwischen zwei Zuwachszonen ist streckenweise scharf abgehoben, oft aber auch verwischt. An der radialen Verkürzung nehmen auch die Markstrahlzellen merklichen Anteil. Dann findet sich in den äußeren Schichten des Spätholzes fast in allen Libriformfasern 
wie auch in den meisten Gefäßen Inhalt, während er im Frühholz in den Gefäßen immer, im Libriform sehr oft fehlt.

Die radial geordneten Libriformfasern besitzen unregelmäßig polyedrischen Querschnitt, eine gelblich gefärbte, 2,6 $\mu$ starke Wand und lassen zwischen sich dreieckige Zwickel frei. Die Wände zeigen spärlich senkrecht übereinanderstehende Hoftüpfel, deren $4 \mu$ großer Hof kreisrund und deren etwas kleinere Mündung spaltförmig und der Längsachse der Faser fast parallel ist. Bei gegenseitiger Berührung der Fasern kreuzen sich die Tüpfel. Neben diesen typischen Libriformfasern finden sich Fasertracheiden, deren Hoftüpfelung ebenso spärlich, deren Hof jedoch größer ist und eine rundliche, oft punktförmige Mündung zeigt.

Das Holzparenchym findet sich äußerst selten, stets einzeln im Libriform oder an Gefäßen. Es ist dünnwandig, wie gewöhnlich gebaut und zart getüpfelt. Oft ist es von einer gelbbraunen harzigen Masse vollgepfropft oder es findet sich diese Masse in Tropfenform darin.

Im Spätholz lagern die Gefäße stets einzeln, im Frühholz auch in regellosen Gruppen bis zu 3 Stück nebeneinander. Ihr Umriß ist rund oder elliptisch mit radial gerichteter großer Achse. Die Längswand ist unverdickt, gelb gefärbt und mit zahlreichen Hoftüpfeln versehen. Der Hof ist kreisrund oder oval und $3 \mu$ groß, der Spalt eng, kleiner als der Hof und horizontal gestellt. Die Gefäßglieder sind kurz, die Scheidewände horizontal oder schwach geneigt und fast ganz resorbiert. Demnach ist die Durchbrechung einfach lochartig. In einigen wurde starke Thyllenbildung gefunden.

Die Markstrahlen weichen den Gefäßen aus, sind 1-3reihig (vorwiegend ein- und zweireihig) und auf dem Tangentialschnitt lang-spindelförmig. Die einreihigen Markstrahlen bestehen ausschließlich aus achsial stark gestreckten »stehenden « Zellen, die mehrreihigen in ihrer Mitte aus »liegenden «, an der Kante aus »stehenden «. Die letzte Markstrahlzelle ist stets spitz. Die »liegenden « Zellreihen treten immer geschlossen 
auf; den Übergang zu den "stehenden « bilden fast in jedem Markstrahl 1 oder 2 Reihen isodiametrischer Zellen. Die Tüpfelung ist reichlich und zart. Grenzt die Radialwand an ein Gefäß, so vergrößern sich die Tüpfel derart, daß 2-3 Gefäßhoftüpfel in einen Tüpfel aufgenommen werden. Die Interzellularen zwischen den »liegenden «Zellen sind sehr eng. Als Inhalt führen sämtliche Zellen die bei den übrigen Elementen erwähnte gelbe harzige Masse oder dunkelgelbe Öltröpfchen.

\section{Dictyandra arborescens Welw.}

leg. Zenker 1641. Kamerun: Bipinde.

Cinchonoideae. B. Gardeninae. Gardenieae.

Das Untersuchungsstück hat $4 \mathrm{~cm}$ im Durchmesser, $1 \mathrm{~mm}$ dicke dunkelbraune Rinde und fast quadratisches, $7 \mathrm{~mm}$ starkes Mark. Mit unbewaffnetem Auge sieht man auf dem Querschnitt die Gefäßporen als sehr kleine helle Punkte und viele stark verwischte, konzentrische Ringzeichnungen. Unter der Lupe sind noch die zahlreichen feinen Markstrahlen als helle, radiale Streifung festzustellen.

Mikroskopisch ist die Jahrringbildung undeutlich. Nur ein einziger zusammenhängender, 4-5 Zellen breiter Ring von tangential gestreckten Libriformfasern ist auf dem ganzen Querschnitt zu erkennen; sonst deuten nur schwach radial verkürzte Libriformfasern und fast unmerkliche Größenunterschiede der Gefäße Grenzen zwischen zwei Zuwachszonen an.

Das Libriform hat einen unregelmäßig polyedrischen Querschnitt und ist radial gelagert. Die Wand ist $2,7-3 \mu$ dick, intensiv gelb gefärbt und umschließt ein rundliches Lumen, das mehrfach so stark ist als die Membran. Diese zeigt reihenweise übereinanderstehende Hoftüpfel mit kreisrundem, 2,6 $\mu$ großem Hof und spaltenförmiger ebenso langer oder etwas längerer, der Längsachse der Faser fast parallel gestellter Mündung. Die Färbung der Membran geht bei längerem Liegen in Wasser verloren. 
Über den ganzen Querschnitt gleichmäßig zerstreut liegt das spärlich entwickelte, stets isoliert stehende Holzparenchym. Es hat eine im Querschnitt höchst unregelmäßige Form und ziegt nie engere Beziehung zu den Gefäßen. Die Wand ist sehr dünn und trägt zahlreiche kleine, einfache Tüpfel. Als Inhalt kommt eine gelbbraune, mit Eisenchlorid sich schwarz färbende harzige Masse vor.

Die Gefäße haben als Querschnittsform eine Ellipse mit radial gestellter großer Achse. Sie lagern isoliert, selten zu Paaren. Die Gefäßwände sind nur schwach verdickt und zeigen links spiralig aufsteigende, nicht allzu zahlreiche Hoftüpfel. Der Hof ist kreisrund, $3 \mu$ groß, die Mündung spaltförmig, fast horizontal gestellt und kürzer als der Hof. Bei Angrenzung der Gefäßwand an Holzparenchym ist der Hof oft horinzontal in die Länge gezogen, bei Berührung mit Markstrahlparenchym tritt keine Änderung der Tüpfelung ein. Die GefäBglieder werden von schwach geneigten Scheidewänden begrenzt, die die Perforation als ein großes rundes Loch zeigen. Die Gefäßlumina des älteren Holzes sind sehr oft durch zarte Thyllen verstopft oder mit gelbbraunem harzigen Inhalt gefüllt. Neben den Gefäßen finden sich auch Gefäßtracheiden, die dieselbe Tüpfelung - nur etwas spärlicher zeigen.

Die Markstrahlen verlaufen auf dem Querschnitt so eng, daß jedes Gefäß auf beiden Radialseiten von ihnen berührt wird. Wie der Tangentialschnitt zeigt, sind sie zum überwiegenden Teil zweireihig, häufig ein-, sehr selten dreireihig. Die den mittleren Teil der mehrreihigen Markstrahlen zusammensetzenden Zellen sind in ihrer radialen Ausdehnung doppelt so lang als hoch - jedoch finden sich auch Reihen von isodiametrischen Zellen eingefügt -, die die kantenbildenden "stehenden " Zellen 3-4 fach so hoch als breit. Die einreihigen Markstrahlen bestehen nur aus »stehenden « Zellen, bei denen das Verhältnis von Höhe zu Breite noch unterschiedlicher wird. Die Markstrahlen werden bis 25 Zellen 


\title{
$-42-$
}

hoch und führen den schon in den übrigen Elementen gefundenen Inhalt. Die Tüpfelung ist äußerst reichlich und einfach.

\section{Randia dumetorum Lam.}

\author{
leg. v. Trotha. D. 1. Ostafrika.
}

Cinchonoideae. Gardeninae. Gardenieae.

Das untersuchte Achsenstück hat einen Durchmesser von $2 \mathrm{~cm}$ und hellbraune Färbung. Jahrringzeichnungen sind stark verwischt. Erst dem mit der Lupe bewaffneten Auge ist es möglich, die Markstrahlen als feine, helle, radiale Streifung und die Poren als kleine helle Punkte zu erkennen. Das Mark hat ovale Form und ist $3 \mathrm{~mm}$ dick. Es ist umgeben von $2-3 \mathrm{~mm}$ starkem Kernholz, das etwas dunkler erscheint als das Splintholz.

Zuwachszonen sind mikroskopisch deutlich wahrzunehmen: Eine Grenze zwischen den einzelnen Zonen wird dadurch hervorgerufen, daß im Frühholz mehr und etwas größere Gefäße liegen, und daß das Libriform hier größeren Zellenquerschnitt zeigt als im Spätholz. Die letzten Libriformreihen wie auch die Markstrahlzellen des Spätholzes sind außerdem noch, wenn auch ziemlich unbedeutend, tangential gestreckt.

Das Libriform zeigt in der Frühholzzone unregelmäßig polyedrischen Querschnitt und streng radiale Anordnung, im Spätholz regelmäßig fünf- oder sechseckige Form und gestörte Lagerung. Seine gelb gefärbte Wand ist $5-5,5 \mu$ dick und mit sehr kleinen Hoftüpfeln versehen, deren Hof länglich ist, deren spaltfôrmige, äußerst schmale Mündung den Hof oft um weniges überragt und der Längsachse der Faser fast parallel steht. Die Spalten und Höfe sind so schmal, daß man auf dem Querschnitt von der Tüpfelung nichts wahrnimmt. Nur im primären Holz findet sich ein gelber, feinkörniger Inhalt, dadurch die Kernholzfärbung hervorrufend. Bei gegenseitiger Anlagerung der Fasern kreuzen sich die Tüpfel.

Die einzeln, selten zu Paaren stehenden Gefäße nehmen 
innerhalb der Zuwachszone allmählich an Größe und Zahl ab (im primären Holz sehr oft zu Paaren). Ihr Umriß ist kreisrund oder elliptisch mit radial gerichteter großer Achse. Die Längswand ist unverdickt und trägt zahlreiche, linksspiralig aufsteigende Hoftüpfel, deren Hof $3 \mu$ groß und deren spaltförmige Mündung sehr schmal und kleiner als der Hof ist. Bei Berührung mit Markstrahlparenchym zeigt sich keine Änderung in der Tüpfelung. Die Gefäßglieder sind lang, die Scheidewände horizontal bis steil geneigt und fast ganz resorbiert, sodaß die Perforation sehr groß, rund oder elliptisch ist. Bei sehr steil geneigten Scheidewänden liegt die Durchbrechung in der Mitte, der übriggebliebene Wandrest ist dann wie die Längswände hofgetüpfelt. Spärlich treten nehen den Gefäßen tracheidale Formen auf, deren ähnliche Hoftüpfelung aber nicht so reichlich ist.

Das Holzparenchym ist sehr sparsam entwickelt und steht isoliert. Es hat unverdickte Membran und kleines Lumen. Tüpfelung und Form ist gewöhnlich. Die Markstrahlen treten äußerst zahlreich auf und haben höchstens 5, meist nur 2 Libriformreihen zwischen sich. Sie sind auf dem Tangentialschnitt lang spindelförmig und aus »liegenden «, isodiametrischen und »stehenden « Zellen derart zusammengesetzt, daß die übereinanderstehenden Reihen des mittleren Teils abwechselnd von radial gestreckten »liegenden « und isodiametrischen Zellen, die Kanten dagegen stets von achsial stark gestreckten, »stehenden " gebildet werden. Eine Verbindung mehrerer Markstrahlen durch die Kantenreihe ist selten. Die Zellen sind alle mit gelblichem, feinkörnigem und gerbsäurehaltigem Inhalt gefüllt. Die Wandstärke ist bei allen Zellen gleich, die Tüpfelung ist reichlich und zart.

\section{Randia acuminata. Benth.}

leg. Staudt. 590. Jaundestation-Kamerun.

Cinchonoideae. Gardeninae. Gardenieae.

Das untersuchte sehr harte, weißlich-gelbe Achsenstück 
hat $3 \mathrm{~cm}$ im Durchmesser. Die allgemein stark verwischten Jahrringzeichnungen sind nur im älteren Holz etwas deutlicher kenntlich. Markstrahlen sind makroskopisch unkenntlich, Poren als äußerst feine, helle Punkte sichtbar. Das Mark ist nur $1-2 \mathrm{~mm}$ groß. Nach Karl Schumann wächst Randia acuminata als kahler Strauch in Westafrika und im Monbuttulande.

Immer sind die Grenzen der einzelnen Zuwachszonen mikroskopisch deutlich sichtbar. Das Frühholz zeichnet sich durch viele und große Gefäße aus, deren Anzahl und Lumen nach dem Spätholz hin allmählich abnimmt (im Frühholz $45-50 \mu$, im Spätholz $20-30 \mu$ ), bis sie in den letzten 5 Libriformschichten ganz verschwinden. Die radiale Verkürzung der übrigen Elemente im Spätholz ist unbedeutend.

Libriform bildet die Grundmasse des Holzes und steht streng radial geordnet. Sein Zellenquerschnitt zeigt verschiedenerlei Form: isodiametrisch, rund oder fast regelmäßig fünfeckig. Die $7,8 \mu$, also sehr dicke Wand ist gelb gefärbt und bedingt die Härte des Holzes. Das Lumen ist im Verhältnis zur Wandstärke sehr klein, oft nur punktförmig. Die Fasern sind mit reihenweise übereinanderstehenden, spärlich vorhandenen Hoftüpfeln versehen, deren spaltenförmige, schiefgestellte Mündung ebenso lang wie der kreisrunde $2 \mu$ große Hof ist. Bei aneinander lagernden Fasern kreuzen sich die Tüpfel. Inhalt führen die Fasern nicht.

Der Umriß des dünnwandigen Holzparenchyms hat stets dieselbe Form, die die jeweiligen Libriformfasern der Reihe besitzen, in der sie eingelagert sind. In den letzten Libriformschichten der Zuwachszone fehlend, steht es sonst vereinzelt oder in sehr kurzen tangentialen Ketten im Libriform oder an den Gefäßen, bei diesen ausnahmslos an der äußeren tangentialen Seite. Es ist recht sparsam, einfach getüpfelt und führt als Inhalt große Stärkekörner.

Auf dem Querschnitt stehen die Gefäße stets einzeln und zeigen fast kreisrunden Umriß mit ziemlich stark verdickter 
Wand. Diese trägt zahlreiche, in linksläufiger Spirale aufsteigende Hoftüpfel mit horizontal gestellter, spaltenförmiger Mündung und kreisrundem, $4 \mu$ großem Hof. Die Gefäßglieder sind kurz, die Scheidewände liegen horizontal, selten schwach geneigt und sind kreisrund oder oval, einfach durchbrochen.

Die Markstrahlen erscheinen auf dem Querschnitt fast ausnahmslos einreihig und in solcher Anzahl, daß fast jedes Gefäß auf beiden Radialseiten von ihnen berührt wird. Auf dem Tangentialschnitt sind sie spitz spindelförmig, 1-4 reihig (meist einreihig) und bis 30 Zellen hoch. Die einreihigen Markstrahlen zählen 5-7 stets achsial sehr langgestreckte "stehende « Zellen. Im mittleren Teil der mehrreihigen Markstrahlen ist in radialer Richtung die Streckung verschieden, aber nie bedeutend. Auf diese »liegenden « Zellen folgen immer ohne Übergang achsial stark gestreckte »stehende". Zellen, die in einer einzigen Reihe, durchschnittlich 4-6 Zellen hoch übereinander stehen. Die äußerste Zelle ist stets spitz und am längsten. Während die Wandstärke der »liegenden "Zellen keine Differenzierung aufweist, finden sich die Tangentialwände der »stehenden " doppelt so stark verdickt als die Radialwände. Als Inhalt findet sich in den »stehenden " Zellen stets Stärke, in den »liegenden " nur selten ein gelber, feinkörniger Niederschlag. Die Tüpfelung ist einfach, spärlich und zart. Nur bei Anlagerung an Gefäße ist eine Vergrößerung der Tüpfelkanäle festzustellen.

\section{Randia micrantha. K. Sch.}

leg. Zenker. 2844. Kamerun.

Cinchonoideae. Gardeninae. Gardenieae.

Vorliegendes Achsenstück ist äußerst hart, mißt $2^{1 / 2} \mathrm{~cm}$ im Durchmesser, hat sehr dünne, unserer Saalweidenrinde ähnliche Rinde und ein fast quadratisches, $4 \mathrm{~mm}$ starkes Mark. Mit freiem Auge sind auf dem schmutzig-gelben Holzquer- 
schnitt nur jahrringähnliche, konzentrische Zonen zu erkennen. Gefäße und Markstrahlen sind erst unter der Lupe kenntlich, jene als kleine Punkte, diese als engstehende, zarte helle Linien.

Mikroskopisch ist keine Jahrringbildung festzustellen. Kein Element zeigt periodische Gestaltsveränderung; nur quantitativ treten die Gefäße und das Holzparenchym verschieden in ringförmigen Zonen auf, die aber nicht kontinuierlich sind. So folgt regelmäßig auf einen gefäß- und parenchymreichen Ring ein an beiden Elementen ärmerer, ohne daß aber ein plötzlicher Absatz stattfindet. Die makroskopisch wahrnehmbare Ringbildung besteht also aus »falschen « Jahrringen.

Das streng radial gelagerte Libriform bildet die $\mathrm{Holz}$ grundmasse und zeigt kleinen Zellenquerschnitt von regelmäßig fünf- und sechseckiger oder quadratischer, sehr scharfkantiger Form. Die Wand ist $7-8 \mu$ stark und ungefärbt, das Lumen stets punktförmig. Die Wände führen senkrecht übereinanderstehende, sehr kleine Hoftüpfel, deren Hof äußerst klein ist, sodaß er sich wohl auf dem Querschnitt ziemlich deutlich abhebt, auf dem Längsschnitt aber kaum festzustellen ist. Die Mündung des Tüpfels überragt ihn und ist spaltförmig, der Achse parallel. Die Fasern sind sehr lang, inhaltslos und allmählich spitz zulaufend.

Isoliert, selten in kurzen tangentialen Ketten und in keiner Beziehung zu den Gefäßen stehend, tritt das Holzparenchym auf. Meist ist es tangential gestreckt rechteckig, sonst unregelmäßig konturiert und stets mit körniger, gelbbrauner, harziger Masse oder mit Stärkekörnern angefüllt. Die Parenchymzelle ist schmal, lang und spärlich, einfach getüpfelt.

Die samt dem Parenchym periodische Anhäufungen erfahrenden Gefäße stehen ausnahmslos isoliert und besitzen kreisrunden oder elliptischen Umriß mit radial gerichteter großer Achse. Die Gefäßwand ist unverdickt und mit sehr vielen kleinen Hoftüpfeln versehen, deren Hof nur $2 \mu$ groß ist. Die Tüpfelmündung ist breitspaltig, von Hofdurchmesser- 
größe oder kleiner. Die Gefäßglieder sind lang, die Scheidewände schwach geneigt oder horizontal und fast ganz resorbiert, soda $\beta$ die Durchbrechung rund und lochartig ist.

Die Markstrahlen sind ein- bis dreireihig, höchst selten vierreihig, auf dem Querschnitt fast nur einreihig. Die mehrreihigen Markstrahlen zeigen in ihrem mittleren Teil wenig radial verlängerte »liegende", an ihren Kanten eine lange Reihe achsial stark gestreckter »stehender " Zellen. Diese Kantenreihe verbindet oft 2 oder 3 Marks'rahlen untereinander, soda $\beta$ solche zusammengesetzten Markstrahlen eine große Höhe erreichen. Die einreihigen Markstrahlen setzen sich nur aus "stehenden "Zellen zusammen, die die Länge, doch nicht die Breite der Holzparenchymzellen zeigen. D Die Wände beider Zellkategorien sind stark verdickt und reichlich von einfachen Poren durchbrochen. In vielen »liegenden « Zellen findet sich je ein großer rhombischer Einzelkristall oder wenig feinkörniger, gelber Inhalt, in den "stehenden " liegen kleine Stärkekörner.

\section{Randia Kuhniana. F. Hoff.}

Mkondokondo. Ostafrika. leg. v. Trotha. 58.

\section{Cinchonoideae. Gardeninae. Gardenieae.}

Zur Untersuchung liegt ein Endstück eines wahrscheinlich als Pfahl gebrauchten $3^{1 / 2} \mathrm{~cm}$ starken Stammstückes vor. Es ist von zahlreichen Larvengängen, die mit feinem, strukturlosem Holzmehl vollgepfropft sind, durchsetzt. Zuwachszonen sind sehr deutlich auf dem hellen Holz zu sehen. Markstrahlen durchziehen den Querschnitt in teils welligen, teils stark gekrümmten feinen, weißen Linien. Das Mark ist nur $1 \mathrm{~mm}$ stark und von der bei weitem stärksten Zone umgeben. Gefäßporen sind selbst unter der Lupe kaum sichtbar.

Die mikroskopische Untersuchung bezüglich der Jahrringbildung zeigt, daß ziemlich scharfe Zonengrenzen vorhanden 
sind. Das Frühholz beginnt mit einem konzentrischen Ring großer Gefäße und mit auffälliger Anhäufung von dünnwandigem, weitlumigen Holzparenchym. Die Verteilung und Größe der Gefäße ist in dem übrigen Teil der Zuwachszone bis auf die letzten Libriformschichten, die nur wenige, kleine Gefäße führen, gleichmäßig. Mit der Anhäufung von Holzparenchym und Gefäßen im Frühholz geht Hand in Hand die Bildung weitlichtigeren Libriforms, während die letzten 2-3 Libriformschichten stärker verdickte und tangential abgeplattete Fasern zeigen. An dieser radialen Verkürzung nehmen auch die Markstrahlzellen auffallenden Anteil.

Das Libriform macht die Grundmasse des Holzkörpers aus, steht nicht in radialer Anordnung und hat unregelmäßig polyedrischen Querschnitt mit rundem Lumen. Auf dem Tangentialschnitt verlaufen die Fasern zwischen den Markstrahlen in welligen Linien, dabei ihr Lumen verengernd oder erweiternd. Sie enden meist in kurzer, oft etwas abgerundeter Spitze und führen $a b$ und an einen feinkörnigen, gelblichen Inhalt. Die Libriformfaser des Frühholzes besitzt bei $7-10 \mu$ Lumengröße eine Wandstärke von $4,5 \mu$, die des Spätholzes eine $5,3 \mu$ dicke Wand mit $5 \mu$ weitem Lumen. Die reichlich vorhandenen Hoftüpfel mit ziemlich steil gestellter Spaltöffnung und $5 \mu$ großem kreisrundem Hof stehen reihenweise übereinander oder steil linksspiralig. Der Spalt ist kleiner als der Hof. Bei Berührung mit Gefäßen entspricht jedem Fasertüpfel ein GefäBtüpfel.

Holzparenchym findet sich auf dem Querschnitt einzeln oder in kurzen tangentialen Reihen zwischen zwei Markstrahlen. Eine Häufung erfährt es bei der Frühholzbildung. Bau und Tüpfelung wie gewöhnlich. Als Inhalt führt es reichlich Stärkekörner.

- Die Gefäße besitzen runden oder ovalen Umriß mit radial gestellter großer Achse und stehen auf dem Querschnitt einzeln, oder im Frühholz in regellosen, sonst radialen Reihen zu 2-5, oft zu Paaren. Die Gefäßglieder werden von hori- 
zontalen bis sehr steil geneigten, nicht ganz resorbierten Scheidewänden begrenzt; die Durchbrechung ist also oval lochartig. Der nicht resorbierte Teil der Scheidewand ist wie die Gefäßwand hofgetüpfelt. Diese Hoftüpfel sind zahlreich vertreten und besitzen einen kreisrunden, $6 \mu$ großen Hof mit kleinerer, spaltenförmiger, horizontal orientierter Mündung.

Die Markstrahlen sind ein- bis vierreihig. Die einreihigen werden 2-7 Zellen hoch und von achsial stark gestreckten "stehenden « Zellen zusammengesetzt. Die mehrreihigen erreichen eine Höhe von 30 Zellen und sind auf dem Tangentialschnitt z. T. gedrungen, z. T. lang-spindelförmig. Die gedrungenen, breiten Markstrahlen laufen schnell spitz zu und enden in einer oder in wenigen übereinander gestellten »stehenden " Zellen. Bei den schmalen, hohen setzt sich der mehrreihige Teil allmählich in eine lange Reihe sehr stark gestreckter "stehender " Zellen fort. Der mittlere Teil des Markstrahls wird überwiegend von isodiametrischen Zellen gebildet, zwischen die nur wenige »liegende " Zellreihen eingeschaltet sind. Sowohl zwischen den isodiametrischen wie auch zwischen den »liegenden " verlaufen radiale Interzellularen.

\section{Randia ochroleuca. K. Sch.}

leg. Zenker. 807. Kamerun.

Cinchonoideae. Gardeninae. Gardenieae.

Das sehr leichte, hellgefärbte, von glatter dunkler Rinde umgebene Holz läßt auf dem Querschnitt als Einzelheiten die Gefäße als kleine helle Punkte und die Markstrahlen als äußerst feine gelbliche Linien erkennen. Jahrringbildung ist weder makroskopisch noch mikroskopisch wahrnehmbar.

Die Grundmasse des Holzes besteht aus radial geordnetem Libriform mit meist rundlichem Querschnitt; es zeigt an demselben eine $3-3,5 \mu$ starke, gelb gefärbte Wand und Tüpfel mit deutlichem Hof. Das Lumen besitzt denselben Tolle. 
Durchmesser wie die Wand, deren Färbung übrigens bei längerem Liegen in Wasser verloren geht. Die Tüpfel stehen übereinander, haben kreisrunden, $2 \mu$ großen Hof und einen sehr schmalen, doppelt so großen, der Längsachse parallel gestellten Spalt als Mündung. Auf den Radialwänden ist der Spalt kleiner. Die inhaltslosen Fasern sind nicht sehr lang und endigen in scharfer gerader oder bajonettartiger Spitze.

Durch seinen gelben Inhalt hebt sich das Holzparenchym auf dem Querschnitt deutlich ab. Es ist reichlich vertreten, steht isoliert oder in kurzen tangentialen Ketten und hat unverdickte Membran mit zahlreichen einfachen Tüpfeln. Isoliertstehend ist es unregelmäßig konturiert, in den Ketten meist tangential gestreckt.

Die einzeln oder zu Paaren stehenden Gefäße haben einen runden oder elliptischen Umriß und unverdickte, gelb gefärbte Wandung. Die Gefäßglieder sind kurz, die Scheidewände horizontal bis steil geneigt und einfach, lochartig durchbrochen. Die steil stehenden Scheidewände zeigen außer der Durchbrechung auf dem übriggebliebenen Wandteil noch Hoftüpfelung wie die Gefäßwand. Diese trägt sehr eng aneinander stehende kleine Hoftüpfel mit $2 \mu$ großem Hof und horizontal oder schief gestelltem, ebenso großem Spalt. Bei anliegenden Gefäßwänden kreuzen sich die Tüpfel.

Die Markstrahlen sind 1-3reihig, auf dem Tangentialschnitt lang-spindelförmig und bis 40 Zellen hoch. Die einreihigen Markstrahlen bestehen stets aus hohen »stehenden" Zellen, die mehrreihigen in ihrem mittleren Teil auf dem Tangentialschnitt aus runden, kleinen, auf dem Radialschnitt aus radial stark gestreckten, niedrigen »liegenden « Zellen und an der Kante aus doppelt so hohen als breiten "stehenden" Zellen. Diese Kantenzellen bilden eine mehr oder weniger lange Reihe übereinander stehender Zellen, die oft einer Verbindung zweier Markstrahlen dient. Die Wände der »stehenden "Zellen sind doppelt so stark als die der »liegenden «. Ganz enorme Verdickung und große Poren erhalten die auf 
einer Gefäßwand senkrecht stehenden Tangentialwände. Die Tüpfelung ist groß und sehr reichlich. Als Inhalt ist eine tröpfchenförmige, gelbe Masse oft nur in Spuren vorhanden

\section{Randia physcophylla. K. Sch.}

leg. Zenker. 1702. Bipinde-Kamerun.

Cinchonoideae. Gardeninae. Gardenieae.

Das untersuchte, sehr harte Achsenstück hat $2 \frac{1}{2} \mathrm{~cm}$. Durchmesser und schmutzig-weiße Farbe. Auf dem Querschnitt sieht man mit freiem Auge stark verwischte Ringzeichnungen und als kleine helle Punkte zahllose Gefäße. Die Markstrahlen sind unkenntlich.

Zuwachszonen sind mikroskopisch nicht wahrnehmbar.

Das streng radial gereihte Libriform zeigt runden, unregelmäßig polyedrischen, in einigen Reihen auch regelmäßig sechseckigen, scharfkantigen Querschnitt. Die Wand ist $5 \mu$ dick, ungefärbt und führt wenige Hoftüpfel; das Lumen ist kleiner, oft punktförmig. Die Hoftüpfel stehen senkrecht übereinander und lassen einen nur $2 \mu$ großen, runden Hof und einen sehr steil stehenden, der Achse der Faser fast parallelen, den Hof überragenden Spalt erkennen. Bei gegenseitiger Berührung Kreuzung der Tüpfel. Nur vereinzelt findet sich gelbe, harzige Masse als Inhalt. Die Fasern enden in langer, scharfer Spitze.

Durch seinen dunkelbraunen Inhalt fällt das Holzparenchym auf dem Querschnitt auf. Es steht einzeln oder in sehr kurzen, tangentialen Reihen und nimmt jeweils die Querschnittsform der Libriformfasern an, in deren Reihe es steht. Es zeigt unverdickte Membran, reichliche, zarte Tüpfelung und ist achsial sehr lang gestreckt und schmal.

Die in sehr großer Anzahl vorhandenen Gefäße lagern einzeln oder zu Paaren radial aneinander gereiht. Ihr Umriß ist stets elliptisch mit radial gerichteter, bis $100 \mu$ großer 
Achse und wird auf beiden Seiten von den zahlreichen Markstrahlen berührt. Hie und da finden sie sich mit gelber, harziger Masse angefüllt. Die Gefäßwand ist unverdickt und zeigt zahlreiche Hoftüpfel, deren kreisrunder Hof $2,7 \mu$ groß ist und deren schief gestellte Spaltmündung Hofdurchmessergröße erreicht. Die Gefäßglieder sind kurz, die Scheidewände schwach geneigt, fast ganz resorbiert. Die Durchbrechung erscheint daher sehr groß, lochartig.

Auf dem Querschnitt verlaufen die Markstrahlen sehr eng, fast immer einreihig. Sie sind auf dem Tangentialschnitt 1-3 reihig, meist zweireihig, bis 30 Zellen hoch und im mittleren Teil aus »liegenden « Zellen zusammengesetzt, zwischen die $a b$ und an auch 1 oder 2 Reihen »stehende " eingesprengt sind. Die Kante wird stets von einer einzigen Reihe übereinander gelagerter »stehender " Zellen gebildet. Diese Reihe verbindet mitunter 2 oder 3 Markstrahlen miteinander und kann enorme Höhe erreichen. Die einreihigen Markstrahlen setzen sich immer aus "stehenden " Zellen zusammen. Die Tüpfelung ist bei beiden Zellarten reichlich und zart. Unterschiede in der Wandstärke bestehen zwischen den »liegenden " und den »stehenden " im allgemeinen nicht, nur sind die auf den Gefäßwänden senkrecht stehenden Tangentialwände der »stehenden « Zellen enorm verdickt und mit größeren Poren versehen. Als Inhalt findet sich eine feinkörnige oder tröpfchenförmige, in einigen Zellreihen auch konsistente harzige, gelbbraune Masse.

\section{Plectronia nitens. Hiern.}

leg. Holst. 8868. Usambara.

Coffeoideae. Guettardeae. Vanguerieae.

Das Holz hat helle Farbe wie unser Edeltannenholz und ist leicht. Auf dem Querschnitt sieht man gleichmäßig gerundete, jahrringähnliche Zonen, die aus breiten hellen und schmaleren dunklen Ringen bestehen. Nach der Peripherie 
hin stehen sie sehr dicht aneinander; an einer Stelle 3 Ringe auf $1 \mathrm{~mm}$. Die Markstrahlen sind mit freiem Auge als ganz zarte, radiale Streifung sichtbar. Die Gefäßporen sind erst unter der Lupe als feine helle Punkte kenntlich.

Aus folgenden Elementen setzt sich der Holzkörper zuhammen: Libriform, Parenchym, Gefäße und Markstrahlzellen. Bezüglich der Zuwachszonen lehrt die mikroskopische Untersuchung, daß die schmalen dunklen Ringe Spätholzzonen darstellen, gebildet aus 7-10 gefäß- und parenchymfreien Reihen von Libriformfasern, die tangential abgeplattet und stärker verdickt sind als die übrigen Holzfasern des Ringes. An dieser radialèn Verkürzung nehmen auf den Zonengrenzen auch die Markstrahlzellen auffälligen Anteil. Nur im Beginn des Frühholzes findet sich metatracheales Holzparenchym, das im übrigen Frühholz vereinzelt steht. Die Gefäße nehmen oft erst in der Mitte der Zuwachszone ihre größte Zahl und ihren bedeutendsten Umriß an, soda $\beta$ also mit dem Beginn des Frühholzes nicht sofort die Bildung von großen Wasserleitungsbahnen Hand in Hand geht und in den Zuwachszonen eine allmähliche $\mathrm{Zu}$ - und Abnahme der Gefäße regelmäßig wiederkehrt.

Von Libriformfasern wird die Grundmasse des Holzes gebildet. Sie haben auf dem Querschnitt fast regelmäßige sechseckige Form und schön radiale Anordnung. Im Verhältnis zu ihrer Lumengröße besitzen die Libriformfasern äußerst starke Wandverdickung; ihre Wand ist durchschnittlich $10 \mu$ dick, ihr Lumen oft punktförmig. Die Libriformfasern sind sehr lang, laufen in eine scharfe Spitze aus und durchziehen das Holz auf dem Tangentialschnitt in langbogigen, geschlängelten Linien. Sie stehen untereinander, wie auch mit Gefäßen und Parenchym, ausschließlich durch zahlreiche Hoftüpfel in Kommunikation. Die Tüpfel haben kleinen Hof und noch kleinere spaltförmige Tüpfelmündung. Inhalt führen die Libriformfasern nicht; auch wurde keine Gabelung festgestellt. Ihre Membran ist schwach gelblich gefärbt. 
Das in keinem Zusammenhang mit den Gefäßen, isoliert zwischen dem Libriform oder an den Markstrahlen stehende Holzparenchym hat unregelmäßig eckigen Zellenquerschnitt. Bei gegenseitiger Angrenzung ist es reichlich mit $4-4,5 \mu$ breiten, einfachen und runden Tüpfelkanälen versehen. Die Tüpfelung zum Markstrahlparenchym ist zarter und weniger zahlreich. Als Inhalt führt es eine ziemlich homogene, gelbbraune Masse, seltener daneben Stärkekörner.

Die Gefäße liegen vereinzelt oder gruppenweise; die Gruppen meist zu Paaren, seltener zu drei in radialer Richtung aneinander gereiht. Sie haben runden Umriß und einen Durchmesser von $30-35 \mu$ bei $2,5-3 \mu$ Wandstärke. Ihre Gefäßglieder werden von verschieden-, meist wenig geneigten Scheidewänden begrenzt und enden dementsprechend teils in stumpfer, teils in längerer seitlicher Spitze. Die Scheidewände sind fast ganz resorbiert und zeigen die Perforation in Gestalt eines großen, runden bis ovalen Loches. Die mit $5,2 \mu$ breitem Hof umgebenen, ovalen Tüpfelkanäle stehen sehr eng und in linksläufiger Spirale. Bei Berührung mit den anderen Elementen wurde keine abweichende Tüpfelung beobachtet.

Charakteristisch sind für Plectronia nitens die Markstrahlen gebaut. Auf dem Querschnitt überwiegen die einreihigen bedeutend, obwohl diese ziemlich selten vorkommen. Auf dem Tangentialschnitt sind die Markstrahlen meist im mittleren Teil 2-4 Zellen breit, laufen schnell spitz zu, um sich an der Kante in einer einzigen Reihe von mehreren, übereinander gestellten, achsial stark gestreckten Zellen fortzusetzen. Oft verbreitert sich diese Reihe wieder zu einem mehrreihigen Markstrahl, sodaß also 2 gewöhnlich geformte Markstrahlen zusammenfließen. Aus dieser Anlage ist das häufige Vorkommen der einreihigen Markstrahlen auf dem Querschnitt zu erklären. Flankiert werden die Markstrahlen von den sich ihrer Form eng anschmiegenden Libriformfasern, seltener von Parenchym. Der erweiterte mittlere Teil des Markstrahls wird von radial langgestreckten und von achsial wenig gestreckten 
Markstrahlzellen gebildet. Die die Kanten des Markstrahls zusammensetzenden Zellen sind sehr oft um das Mehrfache ihrer Breite achsial gestreckt. Die Wände dieser »stehenden « Zellen sind etwas stärker verdickt als die der »liegenden" Zellen; die Tüpfelung ist bei beiden einfach und sehr reichlich. Zwischen den »liegenden « Zellen verlaufen in radialer Richtung zarte Interzellularen. Vereinzelte Markstrahlzellen führen denselben Inhalt wie das Holzparenchym; sehr oft findet sich Speicherung von großen Stärkekörnern.

\section{Vangueria infausta Burch.}

leg. v. Trotha. 84. Ostafrika.

Coffeoideae. Guettardeae. Vanguerieae.

Nach Karl Schumann ist Vangueria infausta ein krüppeliger Strauch mit filzigen Blättern und mispelähnlicher Frucht, heimisch in Mittel- und Südafrika.

Das Holz ist von kaffeebrauner Farbe und äußerst hart. Auf dem Querschnitt sieht man mit freiem Auge in Abständen von $1 \mathrm{~mm}$ viele rundgewellte, schmale helle und breitere dunkle Ringe. Gefäße sind als kleine helle Punkte, die Markstrahlen als äußerst feine, radiale Streifung erst unter der Lupe sichtbar. Das Mark hat ovale Form, ist in seiner großen Achse $3 \mathrm{~mm}$ dick und von einem schmalen hellen Ring umgeben. Nach mehrtägigem Liegen in Wasser färbt sich dieses gelbbraun, und es bildet sich auf dem Boden ein schmutziggelber, schleimiger Niederschlag.

Bei der mikroskopischen Betrachtung zeigt sich echte Jahrringbildung im äußeren Teil der Zuwachszone, in der Nähe der Zonengrenzen sind die Gefäße spärlicher als sonst, bis fehlend, die Querdurchmesser der Gefäße und des $\mathrm{Pa}$ renchyms kleiner, die Wände der Libriformfasern dicker, die Markstrahlzellen - zumal die "stehenden « - in radialer Richtung gekürzt, in tangentialer Richtung breiter und etwas dickwandiger als sonst. Im ersten Frühholz. fehlt das Paren- 
chym. Die hellere Zeichnung des Frühholzes wird nur durch weitlichtigeres, etwas dünnwandigeres Libriform und zahlreichere, größere Gefäße hervorgerufen.

Den Hauptanteil an der Bildung des Holzes nimmt das. Libriform. Seine Zellen haben infolge starker Zusammenpressung einen unregelmäßig polygonalen bis rundlichen Querschnitt, stehen in regelloser, nicht radialer Anordnung und besitzen 6-7 $\mu$ starke Rinde; das Lumen hat geringeren Durchmesser als die mit zahlreichen Hoftüpfeln besetzte Wand. Die Tüpfel haben einen kreisrunden, 5,2 $\mu$ großen Hof und und zur Längsachse der Faser schief gestellte, spaltenförmige Mündung von 4-4,5 $\mu$ Länge; in aufeinander liegenden Zellen kreuzen sich daher die Tüpfel. Bei Angrenzung an Gefäße korrespondiert mit jedem Libriformhoftüpfel ein Gefäßhoftüpfel mit gleich großem Hof. Die Fasern sind sehr lang und gerade zugespitzt. In der Nähe der Gefäße finden sich oft reich getüpfelte, ebenso verdickte, inhaltslose, tracheidale Formen.

Das Holzparenchym verbindet bald in kurzen tangentialen Reihen die Markstrahlen untereinander, bald steht es einzeln oder in kleinen Komplexen. Es führt gelbbraunen Inhalt und zahlreiche nadelförmige Kriställchen aus oxalsaurem Kalk. Diese Kriställchen häufen sich an. den Querwänden der $\mathrm{Pa}$ renchymzellen; hierbei beobachtet man, daß fast durchweg nur ein Ende jeder Zelle mit oxalsaurem Kalk besetzt ist, während das andere Ende nur ganz minimale Spuren davon aufweist, Regelmäßigkeit bei der Ablagerung an einem bestimmten Ende der Zelle besteht nicht, sodaß man bald den Kalk am oberen, bald am unteren Zellende findet.

Die vereinzelt, hie und da $\mathrm{zu}$ Paaren in radialer $\mathrm{Zu}$ sammenstellung liegenden Gefäße sind rund bis elliptisch. Sie werden von den Markstrahlen berührt. Ihre schwach geneigten, fast horizontal gestellten Scheidewände zeigen einfache, runde Perforation, ihre Längswände ausschließlich kleine Hoftïpfel mit quergestellter, spaltförmiger Mündung und 
kreisrundem Hof von $4 \mu$ Durchmesser. Dieselben Tüpfel finden sich auch in Berührung mit Markstrahlparenchym. Inhalt führen die Gefäße nicht. Dịe von Solereder angegebene spiralige Verdickung der Gefäßwände wurde nicht gefunden.

Die Markstrahlen sind 1-2 reihig, ausnahmsweise dreireihig. Sie erscheinen auf dem Tangentialschnitt bis 20 Zellen hoch und bestehen aus kleinen rundlichen »liegenden " Zellen und großen tangential gestreckten »stehenden "Zellen. Die einreihigen Markstrahlen sind immer aus »stehenden « Zellen zusammengesetzt und werden bis 10 Zellen hoch. Die Kanten der Markstrahlen bestehen ausschließlich aus langen, achsial gestreckten Zellen. Die »stehenden « Zellen sind höchstens doppelt so hoch als breit,. meist sogar quadratisch. Die Länge der »liegenden « Zellen beträgt oft das Mehrfache ihrer Höhe. Die Wände beiderlei Zellen sind sehr reichlich und einfach getüpfelt. Beide führen wie das Holzparenchym sehr viel oxalsauren Kalk in Form von Kristallnädelchen an einem Zellende. Vereinzelt lagern einfache und zusammengesetzte Stärkekörner und kleine gelbbraune Tröpfchen öliger Konsistenz in den »liegenden « Zellen. Die Interzellularen zwischen den »liegenden « Zellen sind deutlich wahrnehmbar.

\section{Coffea spathicalyx. K. Sch.}

leg. Zenker. 718. Jaunde-Kamerun.

Coffeoideae. Psychotriinae. Ixoreae.

Zur Untersuchung liegt ein Achsenstück von $1^{1 / 2} \mathrm{~cm}$ Durchmesser vor. Das Holz hat hellgraue Farbe und zeigt auf dem Querschnitt schmale dunkle, spätholzähnliche Zonen auf hellerem Grunde, die in Entfernung von $1-2 \mathrm{~mm}$ voneinander verlaufen. Die Markstrahlen sind erst dem mit der Lupe bewaffnetem Auge sichtbar, Poren auch hierbei nicht. Das sich hell vom Grundton abhebende Mark hat die Form einer eingeschnürten Ellipse und mißt $5 \mathrm{~mm}$ in 
seiner großen Achse; es wird von einem hellen Ring umgeben.

Der erste schwache, das Mark umgebende hellgefärbte Ring ist fast ausschließlich aus weitlichtigem, dünnwandigem Gewebe - Gefäße und Parenchym - gebildet. Die dunkle Ringzeichnung ist charakterisiert durch Verringerung der Anzahl und Größe der Gefäße und durch fast gänzlichen Mangel an Parenchym. Der Übergang zum gefäß- und parenchymreicheren Frühholz ist stark verwischt.

Schön radial geordnetes Libriform bildet die Grundmasse des Holzkörpers. Es hat etwas gelblich gefärbte Membran und runden, durch gegenseitige Pressung oft eckig abgeplatteten Querschnitt. Seine Wandstärke beträgt $10,4 \mu$ bei 3,9 $\mu$ Lumengröße. Die Libriformfaser ist sehr lang, läuft in eine sehr scharfe Spitze aus und trägt ziemlich reichliche kleine Hoftüpfel, deren spaltenförmige Mündung sehr steil, oft sogar der Faserachse parallel steht. Durch diese Hoftüpfel stehen die Libriformzellen sowohl miteinander, als auch mit allen anderen Gewebearten in Kommunikation, besonders reichlich mit den Markstrahlzellen, wobei der Spalt dieselbe Größe besitzt wie der einfache Tüpfelkanal der Markstrahlzellen. Inhalt führen die Libriformfasern nicht.

Parenchym liegt in einzelnen Zellen im Libriform, hie und $\mathrm{da}$ in regellosen, nicht kontinuierlich zusammenhängenden, tangentialen Reihen. Diese Reihen führen oft an Gefäßen vorüber. Es hat unregelmäßigen Querschnitt, unverdickte, von einfachen 3,9 $\mu$ großen Tüpfelkanälen durchbrochene Wände und führt meist Stärke als Inhalt.

$\mathrm{Zu}$ Paaren oder isoliert stehen die Gefäße; im Ring um das Mark zu 2-5, in radialer Zusammenstellung. Sie haben runde bis ovale Querschnittskonturen und radial gestellte große Achse. Die Gefäßglieder sind kurz, ihre Scheidewände sehr steil geneigt, soda $\beta$ die Glieder in einer seitlich verschobenen, scharfen Spitze enden. Die einfache Perforation ist rund oder elliptisch. Die zahlreichen Tüpfel sind in links- 
läufiger Spirale geordnet und rund bis länglich gehöft (Hof $4 \mu)$, die Spalten eng, von Hofdurchmessergröße oder kleiner. Bei Berührung mit »stehenden « Markstrahlzellen münden oft 2-3 Hoftüpfel der Gefäßwand in eine längliche, einfache Perforation der Markstrahlzellen.

Die in der Regel 2-3 reihigen, zahlreichen Markstrahlen sind sehr hoch, besitzen daher äußerst langgestreckte, spindelförmige Gestalt. Ihr mittlerer Teil setzt sich aus »liegenden * und aus wenig achsial gestreckten "stehenden « Zellen zusammen. Dieser Teil beträgt nur einen kleinen Bruchteil der gesamten Höhe des Markstrahls. Die beiden Kanten sind von einer langen Reihe achsial stark gestreckter Zellen gebildet, sodaß man auf den ersten Blick hin versucht ist, diese für Parenchymzellen $\mathrm{zu}$ halten. Diese Kantenzellen haben eine mittlere Höhe von $100 \mu$ und eine Breite von $15 \mu$, die »liegenden " Markstrahlzellen eine Länge von $26 \mu$ und eine Höhe von $13 \mu$. Die Zellreihen in nächster Nähe der » liegenden « Zellen zeigen auf dem Radialschnitt wenig achsiale Streckung, sind sogar öfter quadratisch gebaut. Die Tangential- und Querwände beider Kategorien sind reichlich, ihre Radialwände spärlich mit einfachen, runden Tüpfeln versehen. Beiderlei Zellen führen zahlreiche große Stärkekörner und wenig gelbbraunen Inhalt.

\section{Pavetta Baconia. Hiern.}

leg. Zenker. 700. Kamerun.

Coffeoideae. Psychotriinae. Ixoreae.

Das untersuchte Achsenstück hat $2^{1 / \frac{2}{2}}$ Durchmesser und $0,8 \mathrm{~cm}$ dickes Mark. Jahrringzeichnungen, Markstrahlen und Poren sind makroskopisch unkenntlich. Auf dem Querschnitt sieht man als Einzelheiten nur einen unterbrochenen Ring heller Flecke, der den Umriß des Markes im Großen wiedergibt. Außer diesem Ring findet man noch einzelne 
kleine, zerstreute, helle Komplexe. Das Holz ist von einer sehr dünnen Rinde umkleidet.

Größere, zahlreichere Gefäße und weitlichtigere Libriform- und Markstrahlzellen charakterisieren das Frühholz; radial verkürzte Markstrahlzellen, engere Gefäße und in den letzten 3-5 Schichten tangential abgeplattetes Libriform kennzeichnen das Spätholz.

Das in radialer Anordnung stehende Libriform ist sehr langfaserig, von meist sechseckigem Zellenquerschnitt. Es ist sparsam mit spaltenförmigen Hoftüpfeln versehen, deren Mündung sich der Längsachse der Faser fast parallel stellt und kleiner als der Hof ist. Bei aneinander liegenden Fasern kreuzen sich die Tüpfel. Die Kommunikation mit den anderen Elementen ist dieselbe wie bei Coffea spathicalyx. Die von Michael angegebene spiralige Anordnung der Tüpfel bei $\mathrm{Pa}$ vetta indica konnte ich bei Pavetta Baconia nicht konstatieren.

Das ziemlich spärlich vertretene, dünnwandige Parenchym ist von schmutzig braunem, tröpfchenförmigem Inhalt gefüllt und liegt in einzelnen Zellen bald im Libriform zerstreut, bald lagert es an Gefäßen. (Für Pavette indica gibt Michael auch tangentiale Reihung an). Die den Gefäßen anliegenden Wände sind sehr reich und einfach perforiert. Vereinzelte Parenchymzellen führen auch zusammengesetzte Stärkekörner.

Die Gefäße stehen zum größten Teil isoliert, selten zu $2-3$ radial gereiht. Sie sind ziemlich gleichmäßig über den Querschnitt verteilt. Ihr Umriß ist mehr eckig als rund und hat radial gestellte große Achse von $30-50 \mu$ Länge. Die Membran ist dünn und von vielen linksspiralig aufsteigenden, $4 \mu$ großen Hoftüpfeln besetzt, deren Mündung spaltförmig und fast horizontal gestellt ist. Die Gefäßglieder sind kurz, von schwach geneigten Scheidewänden begrenzt, die fast ganz resorbiert sind und runde oder elliptische Perforation zeigen. Bei Berührung mit dem Markstrahlparenchym und Holzparenchym korrespondiert mit jedem Hoftüpfel ein einfacher Tüpfel an der Parenchymwand. 
Sehr reichlich vorhanden sind die Markstrahlen. Sie sind $1-2$ reihig, bis 20 Zellen hoch und liegen auf dem Querschnitt so eng aneinander, daß sie oft nur durch 2-3 Libriformreihen getrennt werden. An der Bildung des mittleren Teils des spindelförmigen Markstrahls beteiligen sich bei den zweireihigen immer neben den »liegenden " auch »stehende" Zellen. Die »liegenden « Zellen ergeben auf dem Tangentialschnitt fast runden Anblick (Verhältnis von Länge: Höhe auf dem Radialschnitt $3: 1$ ). Oft finden sich als nächste Begleitung dieser typischen »liegenden "Zellen oben und unten teils ganz gering radial gestreckte, teils quadratische oder etwas achsial gestreckte Markstrahlzellen, zwischen denen ebenso wie zwischen den »liegenden «Zellen zarte Interzellularen verlaufen. Nach beiden Kanten hin liegt bei den meisten Markstrahlen wie bei Coffea spathicalyx eine lange Reihe hoher Zellen. Aus diesen Reihen der "stehenden " Zellen erklärt sich die enge Stellung der einreihigen Markstrahlen auf dem Querschnitt. Nur in den Markstrahlzellen, die den Gefäßen direkt auflagern, findet sich reichliche Ablagerung von Stärkekörnern. In allen anderen fehlt sie; dafür tritt Füllung mit denselben braunen, öligen Tröpfchen, wie sie im Parenchym gefunden wurden. Dieser Inhalt ist gerbsäurehaltig. Die Tüpfelung der tangentialen und horizontalen Wände ist bei beiden Kategorien reichlich und einfach; ihre Wandstärke ist dieselbe. 


\section{Ergebnisse.}

Die Familie der Rubiaceen läßt keine einheitlichen Merkmale erkennen, nach denen man sie charakterisieren oder in Gruppen zerlegen kann, die den natürlichen Verwandtschaftsverhältnissen entsprechen. Man möge irgend einen Tribus der bis jetzt von Solereder, Michael und von mir untersuchten Arten zusammenfassen, nie zeigt sich ein anatomischer Charakter durchgehend. Es bleibt mir also nur übrig, Solereders allgemeine Angaben nach meinen Untersuchungen im Folgenden zu ergänzen.

Libriform:

Bei Mussaendeen (Sabicea calycina Benth.) und Gardenieen (Gardenia ramentacea K. Sch., Chomelia grandiflora Hiern.) kommt auch nicht hofgetüpfeltes Libriform vor. Bei Gardenieen ist allgemein der Hof sehr klein. Bei den Vanguerieen, Ixoreen, Cinchoneen, Naucleen wird Hoftüpfelung bestätigt.

Gefä Be:

Einfache Durchbrechung auch auf der Gefäßseite bei Berührung mit Markstrahlparenchym fand ich bei Oxyanthus speciosus P. D. C. (fast unbehöft), Heinsia pulchella (alle Übergänge vom Hoftüpfel zur einfachen Durchbrechung), Gardenia ramentacea K. Sch. (nur einfache Durchbrechung).

Die Scheidewände sind meist horizontal oder schwach, seltener steil geneigt. Die Perforation fand ich immer einfach, rund oder elliptisch, nie leiterförmig. Auf dem nicht resorbierten Wandteil zeigt sich oft noch reichliche Hoftüpfelung. 


\section{$-63$}

Parenchy $\mathrm{m}$ :

Ist allgemein spärlich ausgebildet und steht isoliert im Libriform und an den Gefäßen oder in kurzen, 1-2 reihigen tangentialen Ketten; endlich nimmt es auch hervorragenden Anteil am Aufbau des Holzkörpers dadurch, daß es die Gefäße in ansehnlichen, tangential verlängerten Höfen umgibt (Sabicea).

Markstrahlen:

Sie zeigen selbst innerhalb der Art so große Differenzen in Höhe, Breite und Zusammensetzung, daß sie zu diagnostischen Zwecken kaum auszunützen sind.

Kristalle:

Einzelkristalle: 1) In »liegenden « Markstrahlzellen (Sarcocephalus sambucinus, Heinsia diervilloides, Heinsia pulchella und Randia micrantha).

2) In »stehenden « Markstrahlzellen (Gardenia ramentacea, Drusen).

3) In Kristallkammerfasern (Sabicea calycina Benth.).

4) Kriställchen: Im Parenchym und in den Markstrahlzellen von Vangueria infausta.

Jahrringbildung:

1. Sehr deutlich ausgeprägt bei Vanguerieen, Ixoreen und Cinchoneen.

2. Nicht vorhanden bei Naucleen und Missaendeen außer Sabicea calycina.

3. Bei Gardenieen entweder deutlich ausgeprägt oder nicht vorhanden oder stark verwischt. 


\section{Literatur.}

Engler-Prant1: Die natürlichen Pflanzenfamilien. 4. Teil. Abt. 4. Kny, L. : Ein Beitrag zur Kenntnis der Markstrahlen dikotyler Holz* gewächse. Ber. d. D. Bot. Ges. 1890, 8.

Michael, P. O.: Vergleichende Untersuchungen über den Bau des Holzes der Kompositen Caprifoliaceen und Rubiaceen. Diss. Leipzig 1885.

Möller: Beiträge zur vergleichenden Anatomie des Holzes. Denkschr. d. Akad. zu Wien 1876.

Solereder: Über den systematischen Wert der Holzstruktur bei den Dikotyledonen. 


\section{Lebensiauf.}

Am 1. 8. 1889 wurde ich, Karl Hermann Tolle, als Sohn des Ziegeleibesitzers Karl Tolle zu Großbodungen, Kreis Worbis, geboren. Ich bin preußischer Staatsangehöriger und evangelischer Konfession. Vom 6-10. Lebensjahre besuchte ich die Volksschule zu Großbodungen und trat Ostern 1900 in die Sexta des Kgl. Realgymnasiums zu Nordhausen ein, woselbst ich am 3. März 1909 die Reifeprüfung bestand. Von Ostern 1909 bis Ostern 1911 widmete ich mich in Jena dem Studium der Naturwissenschaften. Ostern 1911 bis Michaelis 1911 studierte ich in München und seit Michaelis 1911. in Göttingen.

Ich besuchte die Vorlesungen und Übungen folgender Herren Professoren und Dozenten:

in Jena: Baedeker, Fecht, Knorr, Plate, Stahl, Stoy, Weinel,

Winkelmann;

in München: v. Aster, Broili, Doflein, v. Groth, Maas;

in Göttingen: Ehlers, Peter, Pompecky, Rieke, Simon, Wallach. 




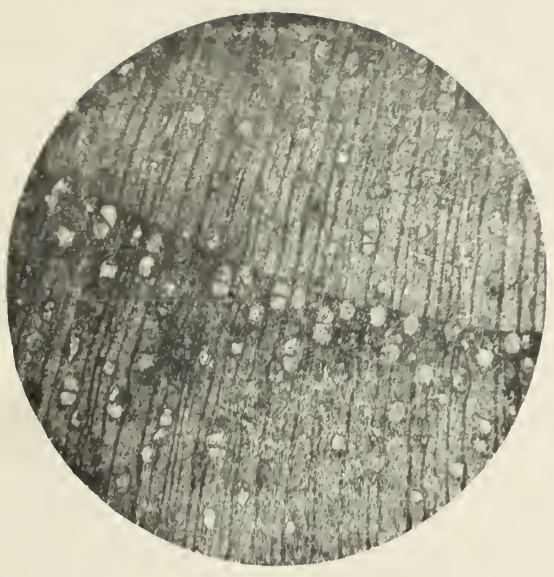

Heinsia pulchella (G. Don) K. Sclı. Usambara. Jahrring. Vergr. 55fach,

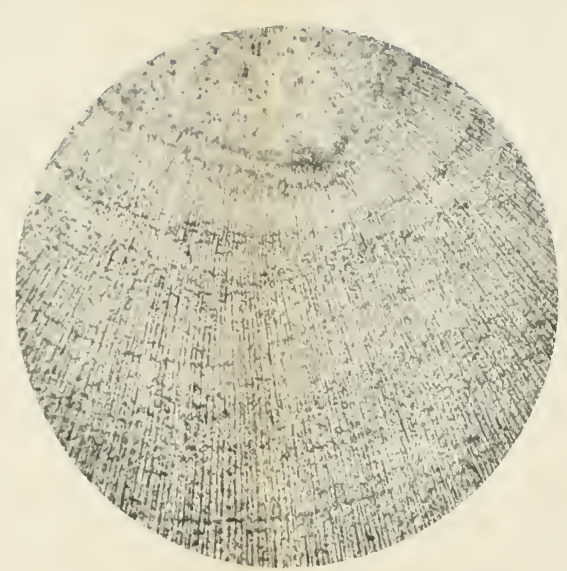

Coffea spathicalyx K. Sch. Kamerun-Jaunde. Vergr. 16 fach.

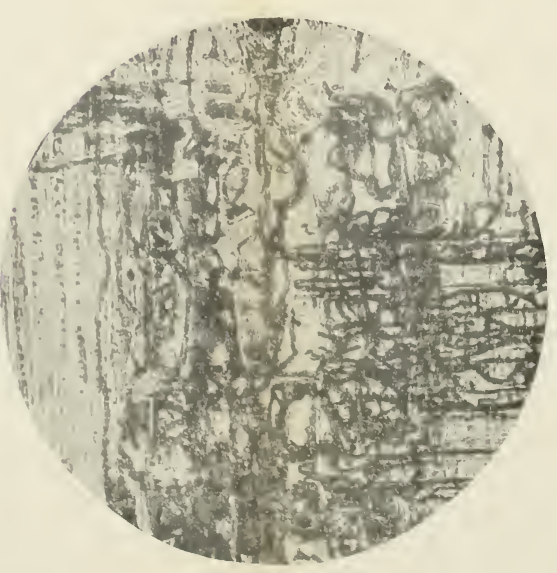

Sabicea calycina Benth. Radial. Pilze in den MarkSabicea calycina Benth. Kimerun-Bipinde. Quer Pilze in den Parenchymhöfen. Vergr. 40fach, strahlreihen und im Parenchym. Veror. 160fach.

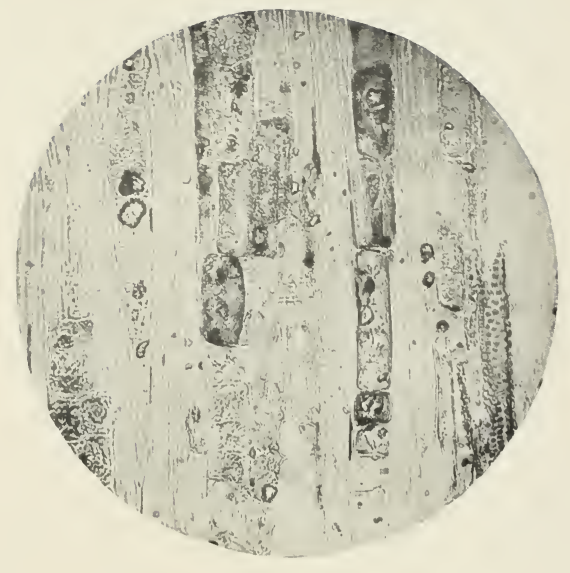

Gardenia ramentacea K. Sch. tang. Kamerun. T. $\rightarrow=$ Vergr. 160fach.

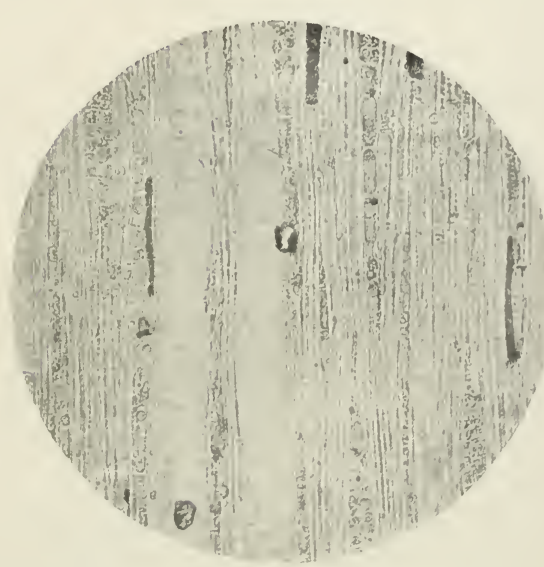

Randia ochroleuca K. Sch. tang. Kamerun. Vergr. 160fach.

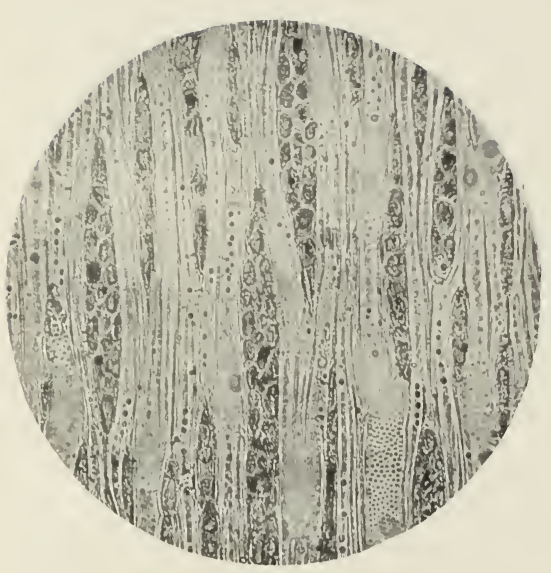

Plectronia nitens Hiern. tang. Usambara. Vergr. 160 fach.

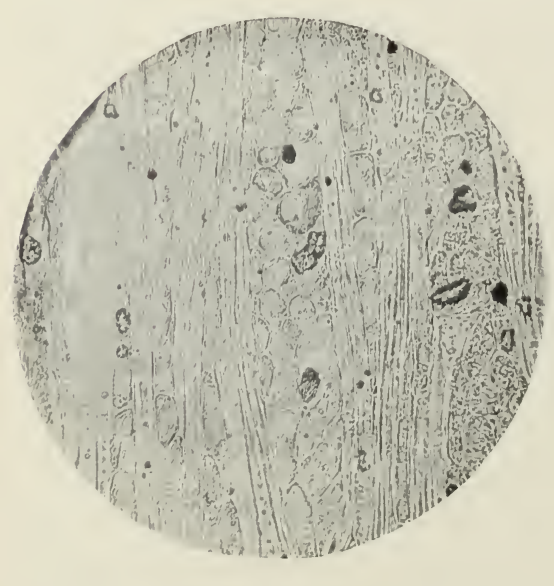

Randia Kuhniana F. Hoff. tang. Ostafrika Vergr. 160fach. 